Portland State University

PDXScholar

\title{
A Feasibility Study of Model-Based Natural Ventilation Control in a Midrise Student Dormitory Building
}

Steven James Gross

Portland State University

Follow this and additional works at: https://pdxscholar.library.pdx.edu/open_access_etds

Part of the Energy Systems Commons, and the Materials Science and Engineering Commons Let us know how access to this document benefits you.

Recommended Citation

Gross, Steven James, "A Feasibility Study of Model-Based Natural Ventilation Control in a Midrise Student Dormitory Building" (2011). Dissertations and Theses. Paper 449.

https://doi.org/10.15760/etd.449

This Thesis is brought to you for free and open access. It has been accepted for inclusion in Dissertations and Theses by an authorized administrator of PDXScholar. Please contact us if we can make this document more accessible: pdxscholar@pdx.edu. 


\title{
A Feasibility Study of Model-Based Natural Ventilation Control in a Midrise Student Dormitory Building
}

by

Steven James Gross

A thesis submitted in partial fulfillment of the requirements for the degree of

\author{
Master of Science \\ in \\ Mechanical Engineering
}

\author{
Thesis Committee: \\ Huafen $\mathrm{Hu}$, Chair \\ David Sailor \\ Graig Spolek
}

Portland State University

(C)2011 


\begin{abstract}
Past research has shown that natural ventilation can be used to satisfy upwards of $98 \%$ of the yearly cooling demand when utilized in the appropriate climate zone. Yet widespread implementation of natural ventilation has been limited in practice. This delay in market adoption is mainly due to lack of effective and reliable control. Historically, control of natural ventilation was left to the occupant (i.e. they are responsible for opening and closing their windows) because occupants are more readily satisfied when given control of the indoor environment. This strategy has been shown to be effective during summer months, but can lead to both over and under ventilation, as well as the associated unnecessary energy waste during the winter months.
\end{abstract}

This research presents the development and evaluation of a model-based control algorithm for natural ventilation. The proposed controller is designed to modulate the operable windows based on ambient temperature, wind speed, wind direction, solar radiation, indoor temperature and other building characteristics to ensure adequate ventilation and thermal comfort throughout the year without the use of mechanical ventilation and cooling systems. A midrise student dormitory building, located in Portland OR, has been used to demonstrate the performance of the proposed controller. Simulation results show that the model-based controller is able to reduce under-ventilated hours to $6.2 \%$ of the summer season (June - September) and $2.5 \%$ of the winter (October - May) while preventing over-heating during 99\% of the year. In 
addition, the model-based-controller reduces the yearly energy cost by $33 \%$ when compared to a conventional heat pump system.

As a proactive control, model-based control has been used in a wide range of building control applications. This research serves as proof-of-concept that it can be used to control operable windows to provide adequate ventilation year-round without significantly affecting thermal comfort. The resulting control algorithm significantly improves the reliability of natural ventilation design and could lead to a wider adoption of natural ventilation in appropriate climate zones. 


\section{Acknowledgements}

I would like to thank Dr. Huafen Hu for her tireless efforts throughout this project. This research would not have been possible without her support and guidance.

I would also like to thank Dr. David Sailor and all of the members of the Green Building Research Lab at Portland State University. Their knowledge base was crucial to the development and success of my work.

The BHB facilities employees also deserve recognition for allowing me access to the building and utility data. 


\section{Table of Contents}

Abstract

i

Acknowledgments

iii

List of Tables

v

List of Figures

vi

1. Introduction 1

2. Research Methods

3. Case Study: Broadway Housing Building 15

4. Custom Model-Based Controller Development 32

5. Results 45

6. Conclusions 65

References 68 


\section{List of Tables}

Table 1: Summer Temperature Statistics for Portland OR

20

Table 2: Blower Door Test Results 25

Table 3: Predicted Flowrate Correction Factors 39

Table 4: Annual Energy Comparison 65

Table 5: Entire Building Performance Statistics 67 


\section{List of Figures}

Figure 1: EnergyPlus Temperature Algorithm for Natural Ventilation 6

Figure 2: Control Implementation Flowchart 10

Figure 3: A Simplified Methodology Flowchart 11

Figure 4: Acceptable Operative Temperature Range for Naturally Conditioned Spaces_14

Figure 5: Google Earth Rendering of the BHB 15

Figure 6: BHB Floor Plan 16

Figure 7: BHB Neighborhood Map 27

Figure 8: Sample Wind Pressure Coefficient Output from Cp Generator 28

Figure 9: Temperature Control Algorithm 30

Figure 10: Data Flow for Model-Based Algorithm 35

Figure 11: Comparison of Actual Flowrate and Predicted Flowrate 37

Figure 12: Model-Based Control Logic Flowchart 39

Figure 13: Distribution of Ventilation Flowrates 40

Figure 14: Weibull Curve Fit to Under-Ventilated Flowrates 42

Figure 15: Weibull Curve with 5\% Probability Threshold 42

Figure 16: Typical Summertime Window Operation Line Graph - Zone 11 48

Figure 17: Summer Average Ventilation Comparison 49 
Figure 18:Summer Hours Under-Ventilated Comparison 50

Figure 19:Distribution of Flowrates when Under-Ventilated for Summer 51

Figure 20: Summer Hours Under-Ventilated for the MB Controller 52

Figure 21: Summer Hours Over-Heated 53

Figure 22: Summer Degree-Hours Over-Heated 54

Figure 23: Typical Wintertime Window Operation Line Graph - Zone 11 56

Figure 24: Winter Average Ventilation Rate 57

Figure 25: Winter Hours Under-Ventilated 58

Figure 26: Winter Hours Under-Ventilated for the MB Controller 59

Figure 27: Distribution of Flowrates when Under-Ventilated for Winter 60

Figure 28: Energy Consumption Comparison 62 


\section{Introduction}

This research investigates the feasibility of using a fully automated control system to optimize natural ventilation performance through operable windows, using a student dormitory building as a case study. The controller is evaluated based on its ability to: (1) meet the ventilation requirements set forth by ASHRAE standard 62.1, (2) maximize passive cooling in the summer, and (3) minimize the heating load due to overventilation in the winter.

\subsection{Background}

Today, U.S. buildings are consuming $40 \%$ of our total energy and HVAC systems, by far the largest consumer (DOE 2009), account for $41.6 \%$ of that. Natural ventilation has regained popularity in the ongoing campaign to reduce this demand. Operable window natural ventilation systems provide an alternative to mechanical ventilation that can result in a $20 \%$ to $50 \%$ reduction in cooling and ventilation related energy use (Torcellini et al. 2006). The term operable window simply refers to a window that is able to open and close; opposed to exterior glazing windows, which are non-operable and serve mainly as an aesthetic feature and daylight source.

Prior to the innovation of mechanical refrigeration, natural ventilation was universal to all buildings and the primary means of bringing fresh outside air into our living spaces. However, with the advent of modern air conditioning, this trend 
disappeared quickly. The emphasis of design became to minimize, or even eliminate, the outside air entering a building, often resulting in the disappearance of operable windows. This resulted in a common problem known as "sick building syndrome" (SBS) (Redlich et al. 1997). Over time, contaminants accumulated in these buildings and occupants would report inconveniencing symptoms such as difficulty breathing and chronic illness. In order to counteract SBS, building codes, and regulations began to specify a minimum ventilation rate that building mechanical systems must maintain to ensure a healthy indoor environment. This solved the problem of SBS, however it also resulted in a significant increase in the energy demand by on the HVAC system.

Today's engineers seek to reduce the energy demand of our buildings by taking advantage of natural ventilation to replace traditional HVAC systems. By incorporating operable windows in each zone, the fan energy required to provide ventilation air can be eliminated. In addition, natural ventilation can provide passive cooling during the summer whenever ambient temperature becomes favorable. Extensive research in occupant comfort has revealed that residents of naturally ventilated buildings are accepting of a wider range of indoor temperature variation compared to those living in buildings with HVAC systems. Previous research has shown that occupants still feel comfortable when indoor temperature reaches $29^{\circ} \mathrm{C}$ while $25^{\circ} \mathrm{C}$ is often demanded in buildings with HVAC systems (Brager \& Baker 2009). When implemented in the appropriate climatic region, such as the North-West United States, $98 \%$ of the yearly 
cooling load can be met with natural ventilation while providing $90 \%$ of occupants with acceptable conditions (Axley 2001).

\subsection{Controlled natural ventilation}

Although natural ventilation systems have the potential to be an effective alternative to traditional HVAC systems, the critical issue preventing widespread adoption is controllability. The magnitude of the airflow rate through operable windows varies widely depending on building geometries, ambient temperature, wind speed, wind direction, etc. The design challenge is to control the window opening as a function of the ambient and indoor environmental conditions so that the ventilation and thermal comfort requirements are met. Current practice is to leave the control of operable windows to occupants or to implement simple venting schedules, which can lead to a variety of problems. Occupants often neglect or forget to open and close operable windows when outdoor conditions vary unpredictably. It leads to either potential thermal comfort problems or unnecessary energy waste that is required to compensate. This approach simplifies the building's control system but introduces the potential for misuse, and can undermine the energy savings from passive cooling

A high performance controller is able to respond in real-time to changing indoor and outdoor conditions. The diurnal cycle is critical to natural ventilation strategies because much of the heat accumulated during the peak of a summer day is expelled through night ventilation. The faster the controller can respond to changes in the 
ambient conditions, the more likely it is to prevent an over-heating or over-cooling situation.

Another desirable trait for many controllers is to have a small number of possible control positions. This is not necessary for every strategy, but rule extraction (MayOstendorp et al. 2010) and fuzzy-logic based (Eftekhari \& Marjanovic 2003) controllers must choose one control action from a database of possible outcomes. Minimizing the number of possible outcomes reduces the processing time for the control decision. In addition, this prevents constant micro-adjustment of the window, which is not likely to significantly affect the performance.

Daly ( 2002) conducted a case study that shows that without the proper control strategy, natural ventilation systems also invite the potential to consume more energy than a building with a conventional HVAC system. If occupants are allowed to operate windows while the HVAC system is in operation, a building could consume a potential of $32 \%$ more energy compared to the same building with traditional HVAC systems.

However, if rules are set to prevent operable windows and HVAC systems open/turned on simultaneously the same building can achieve $30 \%$ energy savings compared to traditional HVAC system arrangements.

A research project that was conducted at Portland State University (Moody 2009)evaluated the energy consumption compared to window use for a dormitory style residence. This study placed measuring equipment in 30 double occupant dorm rooms with an occupant-controlled operable window and a space heater. The researchers 
collected inside and outside temperature and window operation on a continuous basis for five months. The dorm room units did not have the ability to cool the space, making the operable window the only form of cooling. This study found that while the energy consumed by each dorm was less than pre-construction LEED requirements, the occupants did not operate their windows in an effective manner. Their findings were that operable windows could significantly increase energy consumption when they are not integrated into the building's control system. Data showed that many occupants turned on their heaters while the windows were fully open. This suggests that the occupants were not energy conscious while operating the operable windows.

\subsection{Model based predictive control}

One classic algorithm to control operable windows is to proportionally open the windows as a function of the difference between indoor air temperature and ambient air temperature as shown in Figure 1. This algorithm is designed to provide passive cooling when outdoor conditions are favorable. A previous study (Gross \& Hu 2011) showed that this algorithm is capable of maintaining the thermal comfort for a midrise student dormitory for about $99 \%$ of the cooling season. While zone over-heating was virtually eliminated throughout the summer, this study did not address the ability of this system to provide acceptable ventilation year-round, nor its energy consumption.

Model-based control relies on a building energy/airflow network model to predict how zone temperature will be influenced by variable outdoor conditions, 
modular window openings, and building systems. Model-based control works by running a virtual building model parallel to the building's actual operation. The model can estimate the building's response to multiple future control scenarios, and proactively choose the one that leads to the most desired building performance according to a set of objectives.

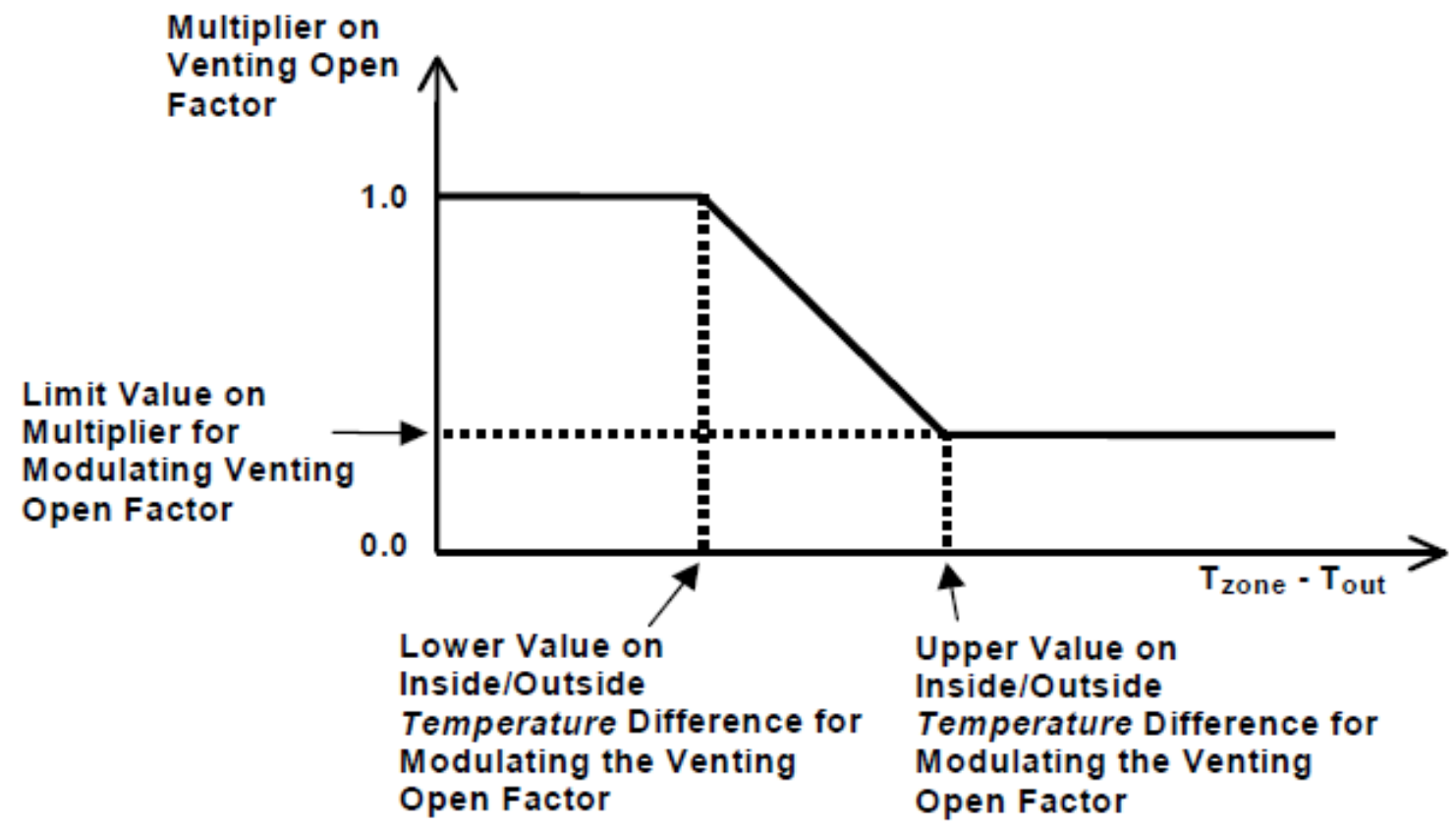

Figure 1 EnergyPlus Temperature Algorithm for Natural Ventilation

May-Ostendorp ( 2010) developed a model-based control algorithm using rule extraction for use in a small office building in Boulder, Colorado. They compared their fully automated controller with the Humphreys Algorithm for occupant window control, as well as the standard DOE benchmark building without natural ventilation. Simulation results show that their predictive controller achieves a 90\% energy savings when 
compared with the occupant control algorithm and $70 \%$ energy savings over the DOE benchmark.

Spindler and Norford ( 2007) developed a model-based control algorithm that considers the weather forecast for the upcoming 24-h period. The test building considered in this study has mechanical fans available to assist natural ventilation. Their controller optimized the nighttime use of the assist fans to prevent over-heating during the daytime. This algorithm requires historical zone temperature data from the test building in order to predict the combination of weather conditions (temperature and wind speed) that typically cause the building to over-heat. When the forecast calls for these unfavorable conditions during the upcoming day, the model-based controller knows to use the mechanical fans during the night to purposely over-cool the space. This helps to prevent over-heating during the next day.

As previous research shows, model-based strategies can be used to predict and control a variety of parameters. While May-Ostendorp's study attempted to minimize the energy consumption required to maintain thermal comfort, Spindler and Norford's study was more concerned with preventing over-heating during the peak of afternoon. The present research postulates that a model-based controller capable of predicting and preventing under-ventilation would be a major advancement in natural ventilation control. 


\subsection{Research Objective}

The objective of the research presented here is to investigate the feasibility of using controlled natural ventilation through operable windows to maintain both ventilation requirements and thermal comfort in midrise dormitory buildings in the mild marine west coastal climate. In addition, the energy impact of using controlled natural ventilation over a traditional HVAC system is be investigated.

A case study is performed using an existing midrise dormitory-style building in Portland, Oregon as a means of evaluating different natural ventilation control strategies. A virtual model is created in EnergyPlus that represents the real-world building, and MATLAB is used to incorporate the operable window control strategies developed through this research. A building controls virtual test bed (BCVTB) is used to evaluate building performances when its operable windows are controlled through different algorithms. The research methodology of this thesis includes three main components:

- Establishment of a baseline for controlled natural ventilation for the case study building, using a classic temperature-based control algorithm.

- Development of model based predictive controller.

- Development of a hybrid controller that combines simple rules with the modelbased controller. 


\section{Research Methods}

This research evaluates the performance of the proposed controllers through

virtual experimentation, i.e. computer simulation. A virtual representation of the case study building is developed in EnergyPlus (Crawley et al. 2000). The proposed control algorithms are programmed in MATLAB (MathWorks Inc 1992). Then, each proposed control algorithm is tested and evaluated on the case study building model through a virtual test bed, called Building Controls Virtual Test Bed (BCVTB). BCVTB is an open source tool that allows multiple simulation programs to be interfaced with each other (Wetter \& Haves 2008). The diagram in Figure 2 shows how BCVTB acts as a "middleman". Zone temperatures are sent from EnergyPlus to MATLAB at the end of each simulation timestep. Then, MATLAB is used to run the control algorithm and send the window position back to EnergyPlus. Finally, EnergyPlus begins the next simulation timestep using the newly calculated window position. 


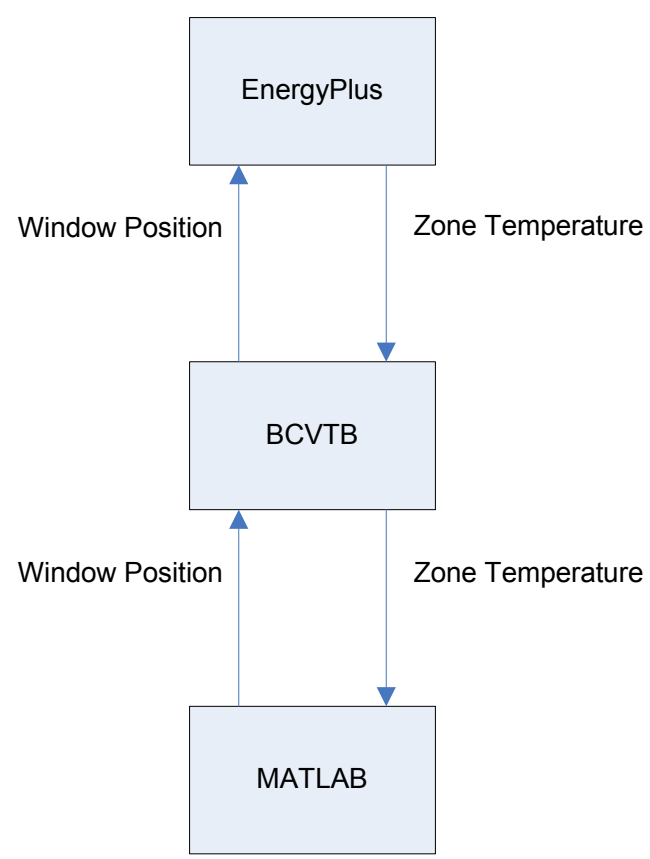

Figure 2 Control Implementation Flowchart

\subsection{Simulation Methods for the Case Study Building}

EnergyPlus, a leading building energy simulation tool, is chosen as the simulation software package of this research for several reasons. First, recent improvements to EnergyPlus allow an airflow model and energy model to be fully integrated (Gu 2007).

This avoids the complication of modeling natural ventilation and its impact to building energy performance in coupled simulation environments, such as EnergyPlus and COMIS (Mehta 2005), TRANSYS and CONTAM (McDowell et al. 2003), etc. Second, EnergyPlus provides built in support for weather data as well as wind pressure coefficient data from external sources. Lastly, the open source nature of EnergyPlus allows for third party software interfacing which can be used to implement custom designed control strategies for operable windows. 
The critical issue when creating an accurate building energy model is to represent the real-world boundary conditions as closely as possible. For this study, great care was taken to characterize the actual airflow paths and wall constructions under investigation. Utility data, field measurements, and specialized engineering tools are used in order to develop a representative model to estimate the natural ventilation rate through operable windows in a midrise institutional dormitory. Figure 3 shows a simplified flowchart of this approach.

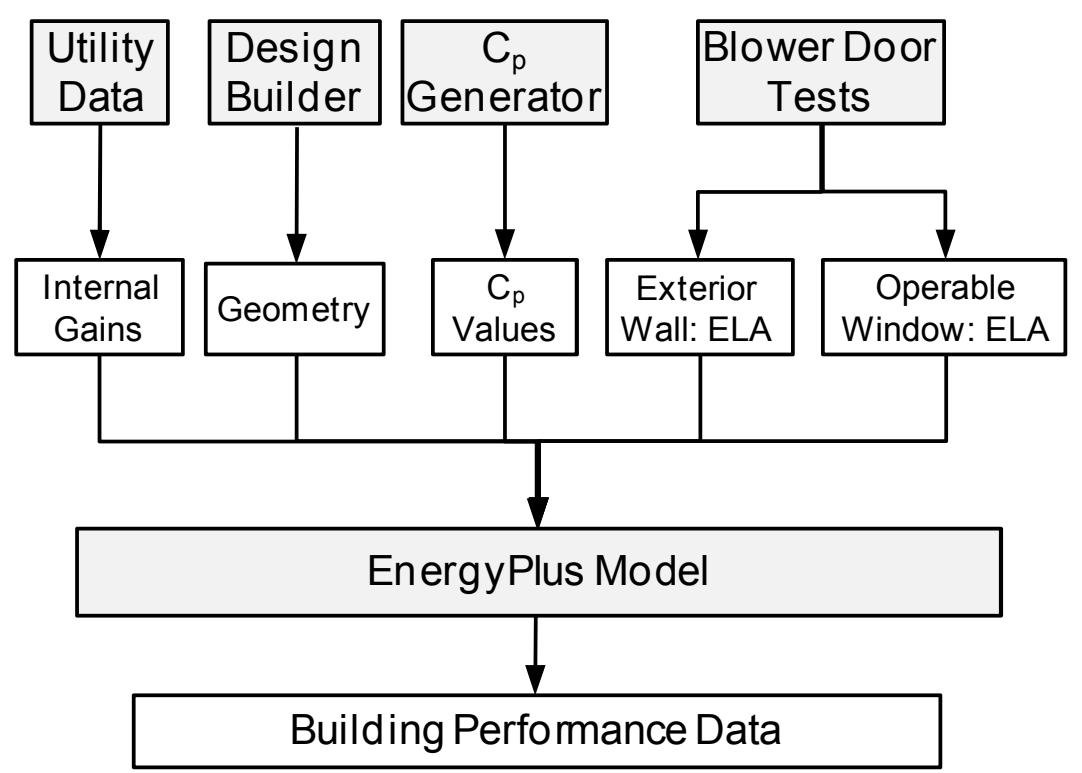

Figure 3 A simplified methodology flow chart

Utility data are collected to provide an estimate of internal gains in the dormitory building; blower door tests are conducted to estimate natural ventilation model parameters for operable windows; DesignBuilder is used to construct a 3-D model and all external Airflow Network nodes; and Cp Generator is used to estimate 
wind pressure coefficients of building facades. Details of each component are presented in the case study chapter.

Real world, in-situ airflow measurements would be ideal when evaluating any natural ventilation system. However, this type of investigation requires long term and invasive (to the occupant) data collection, as well as significant financial resources. Using an EnergyPlus model with a fully integrated airflow network allows multiple scenarios to be tested in a relatively short time and can provide a year's worth of data in one simulation run. While a virtual building cannot perfectly recreate real world behavior, it does provide insight into system behavior in response to variations in operating condition. Careful analysis of simulation results can help the control designer to compare different strategies, and to identify critical parameters in natural ventilation design.

\subsection{Performance Indicators and Evaluation Criteria}

Natural ventilation performance is investigated from two main performance aspects in this study: ventilation rate and thermal comfort criteria set forth by the corresponding ASHRAE standards 62.1 and 55, respectively. In addition, the year-long energy consumption is investigated. The most useful way of gauging ventilation performance is to determine the amount of time a zone is under-ventilated, and by how much. The minimum acceptable ventilation rate provided by ASHRAE 62.1-2004 is

$0.0071 \mathrm{~m}^{3} / \mathrm{s}$ (15 CFM) per person (ASHRAE 2004a). The zones in the case study building 
are intended to house 2 persons. Therefore, any time-step where the infiltration rate falls below the two-person requirement for outside air $\left(0.0142 \mathrm{~m}^{3} / \mathrm{s}\right.$ or $\left.30 \mathrm{cfm}\right)$, the zone is considered under-ventilated for the entire time-step. In order to gauge the degree to which under-ventilation occurs, the distribution of under-ventilated flowrates is also considered. The average ventilation rate is used as a general metric of the effectiveness of ventilation. .

The indoor thermal comfort performance is measured by calculating both the number of hours and degree-hours that each zone is over-heated. Figure 4 shows the range of acceptable indoor temperatures in a naturally ventilated space, which is specified in ASHRAE 55-2004 ventilation code (ASHRAE 2004b). The 90\% acceptability limits is used in this study, i.e. $90 \%$ of the occupants should feel comfortable if natural ventilation manages to regulate indoor temperature within this range. The acceptable temperature range is determined on a monthly basis. For example, if the average temperature for the month of August is $20^{\circ} \mathrm{C}$, the acceptable temperature range is between $21.5^{\circ} \mathrm{C}$ and $26.5^{\circ} \mathrm{C}$. Then a zone will be considered as being overheated if its temperature rises above the $26.5^{\circ} \mathrm{C}$ in August at a given time step. Under-ventilated hours are calculated by simply summing the total number of timesteps where underventilation occurs and dividing by 4 (the number of timesteps per hour). Over-heated degree-hours ( $\mathrm{OHDH})$ are calculated using Equation 1 and summed over the simulation period.

$$
O H D H=\Delta t_{O H}\left(T_{\text {zone }}-T_{\text {upper limit }}\right)
$$


where, $\mathrm{OHDH}$ is the over-heated degree-hours, $\Delta \mathrm{t}_{\mathrm{OH}}$ is equal to the length of the time step, $T_{\text {zone }}$ is the zone operative temperature at each time step, and $T_{\text {upperlimit }}$ is the upper limit of acceptable temperature from ASHRAE 55-2004.

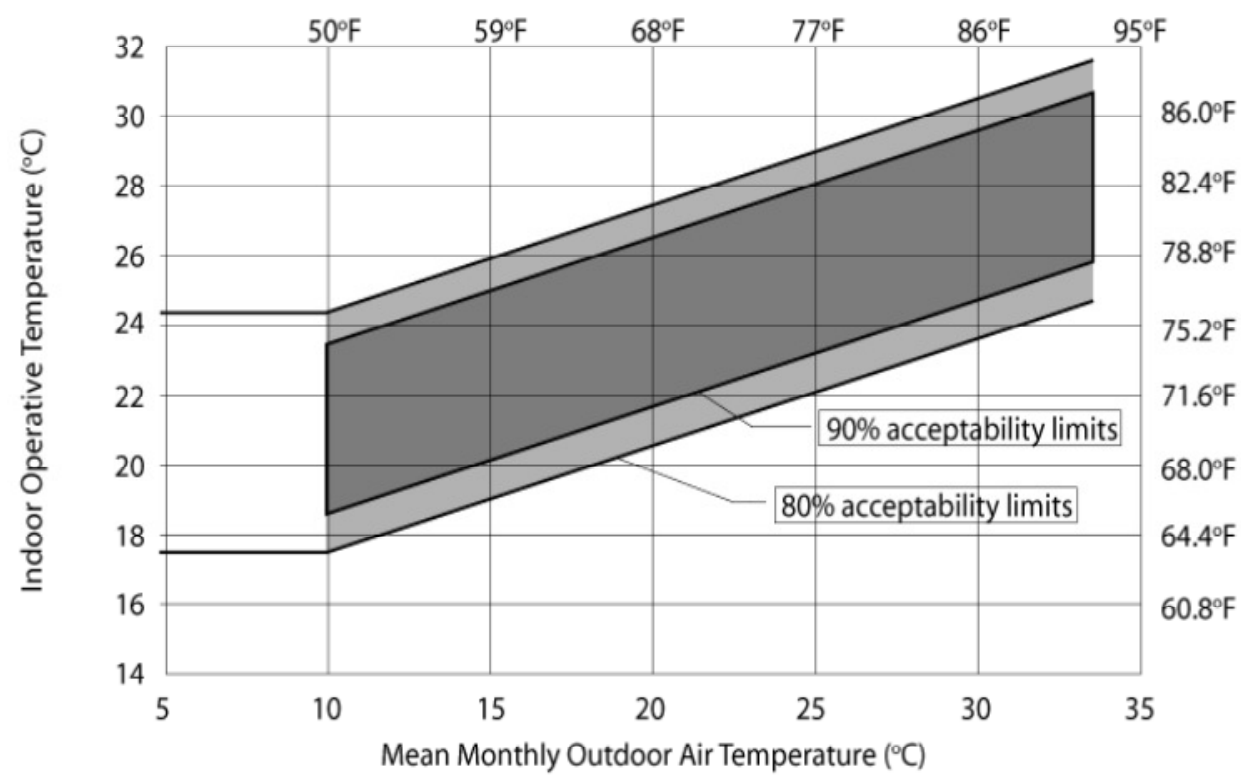

Figure 4 Acceptable Operative Temperature Range for Naturally Conditioned Spaces (ASHRAE 55-2004)

During the winter season, the air introduced from the outside for ventilation purposes is generally cooler than the desired zone temperature. Therefore, a certain amount of energy will be consumed by the heating system to raise the temperature of the incoming air. The goal of the controller, then, is to minimize the amount of energy used, while simultaneously maintaining the ventilation rate requirements, which is first priority. The energy performance of the natural ventilation controllers will be evaluated by comparing the resulting yearly power consumption with that of a typical HVAC system installed in the same building. 


\section{Case Study: Broadway Housing Building}

This chapter provides a detailed description of the Broadway Housing Building (BHB) and the development of the EnergyPlus model used to evaluate the performance of different natural ventilation controllers. This includes development and validation of the multizone airflow network, in-situ airflow path characterization, and a review of natural ventilation strategies. Figure 5 shows a rendering of the BHB taken from Google Earth (Google Inc 2011).

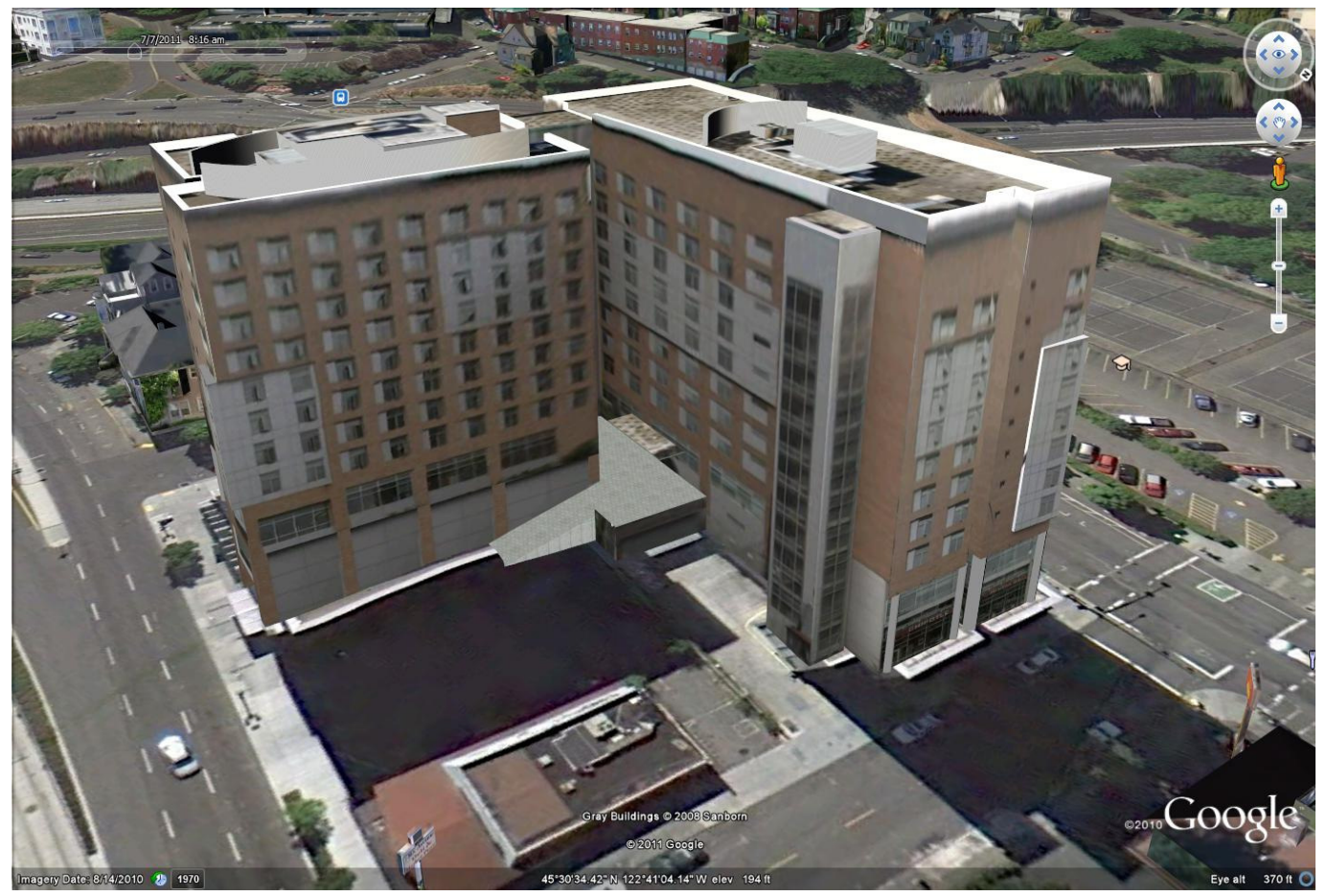

Figure 5 Google Earth Rendering of the BHB

\subsection{Building Description}

The Broadway Housing Building (BHB) is a ten-story midrise student dormitory building located in downtown Portland, Oregon. It consists of eight floors of student 
dormitories, one floor of classroom and office space, and one floor of retail that occupies the sidewalk. The BHB is a LEED Silver building first occupied in 2005. This study only focuses on the dormitory floors because the first two floors are mechanically ventilated and have no impact on the data presented here. Figure 6 shows a representative floor plan of the eight dormitory floors.

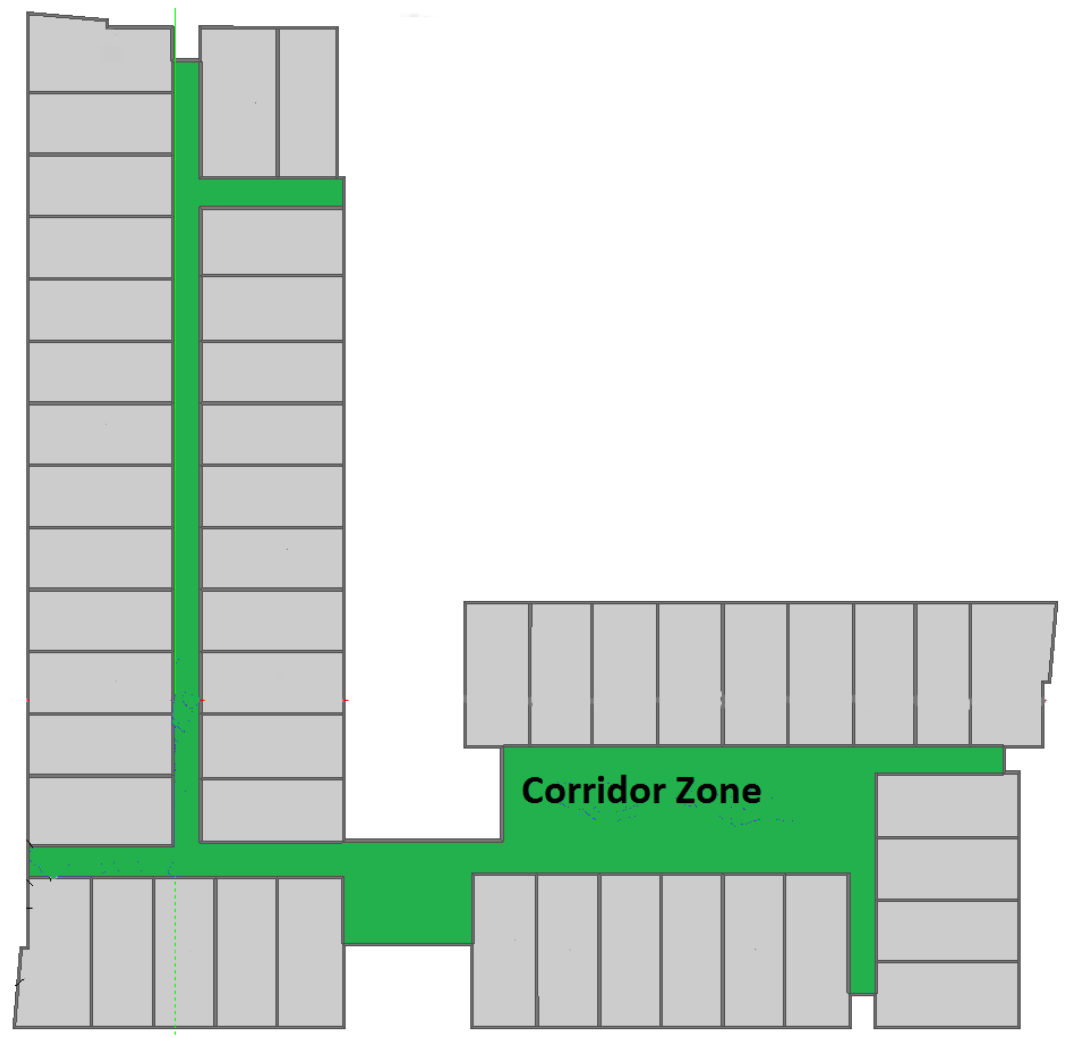

Figure 6 Broadway Housing Building Floor Plan

The BHB's L-shaped floor plan consists of 49 naturally ventilated dormitories connected by a common access corridor, which is mechanically ventilated and conditioned year-round. Each dormitory is intended to house a maximum of two individuals. The typical dormitory layout consists of one bathroom and one large living space totaling about $28 \mathrm{~m}^{2}$ of floor area. The dormitories are designed to be ventilated 
through one operable window in conjunction with continuous (no occupant control) bathroom exhaust. The operable window provides ventilation air even when it is closed due to the "leakiness" associated with the window frame and exterior walls. The exhaust fan creates a negative pressure, which induces inter-zonal flow through cracks in the door that connects to the corridor, and thereby draws a certain amount of conditioned air into the dormitory from the corridor. Except for those on the corners of the building, each dormitory has only one exterior wall and one operable window. Every dormitory is equipped with a baseboard heater controlled by a wall-mounted thermostat. There is no mechanical cooling or ventilation systems in the individual dormitory.

This building is chosen for this case study for several reasons. First, its location in the mild marine west coastal climate makes natural ventilation feasible for year-round comfort. A previous study found that $98 \%$ of the yearly cooling load could be met using natural ventilation in this particular climate (Axley 2001). The weather patterns do not vary much from day to day, and temperature extremes are rare and short-lived. Table 1 shows summer ambient temperature statistics for Portland based on the typical meteorological year (TMY) weather data set used in EnergyPlus (Wilcox \& Marion 2008). Second, previous studies on the same building have shown that many occupants use their windows in a manner that wastes energy and degrades the thermal environment. Another important reason is that very few, if any, natural ventilation studies have been performed on a high occupancy, densely zoned building like the BHB. Numerous control 
studies exist that involve buildings with open floor plans with only one or two zones per floor. However, with almost 400 independent zones, the BHB presents a unique control challenge.

Table 1 Summer Temperature Statistics for Portland OR

\begin{tabular}{|c|c|c|c|}
\hline & $\begin{array}{c}\text { AVERAGE } \\
\text { TEMP (C) }\end{array}$ & $\begin{array}{c}\text { MAXIMUM } \\
\text { TEMP( C) }\end{array}$ & $\begin{array}{c}\text { MINIMUM } \\
\text { TEMP( C) }\end{array}$ \\
\hline JUN & 17.6 & 33.3 & 9.4 \\
\hline JUL & 19.9 & 37.8 & 12.2 \\
\hline AUG & 20.1 & 36.7 & 11.1 \\
\hline SEPT & 17.3 & 33.3 & 7.2 \\
\hline
\end{tabular}

In general, there are two types of natural ventilation strategies: cross-flow and single-sided, or single-opening ventilation. The cross-flow configuration utilizes windows on opposite facades to induce flow through the living space. The windows on the windward façade allow air to enter the space, while windows on the leeward façade allow air to exit. Single-sided ventilation, the strategy used in most BHB zones, utilizes a single window to introduce outside air into the space. Because mass must be conserved, the amount of air entering the space must be equal to the amount leaving the space at any given time. This results in two-way flow through the window. Approximately half the area is used for incoming flow and the other half allows air to exit.

While single-sided ventilation is less effective than the cross-flow strategy, it is well suited to the dorm room application. According to design rules of thumb, the zone should not be deeper than $10 \mathrm{~m}$ from the operable window (Allard \& Santamouris 1998). The dorm layout is shallow enough to permit effective ventilation of the entire space.. 
The BHB's dorm rooms are $8.5 \mathrm{~m}$ deep, so air stagnation is prevented. Second, the densely zoned layout of the BHB would not allow for reliable cross-flow ventilation. In order for air to pass from one façade to another through multiple zones, there must be a flow path. This would require residents to keep their entry door open in order to enable ventilation. Privacy and security concerns make this option impractical.

\subsection{Model Development}

The building model for this study was developed using data from a variety of sources. The in-situ flow paths are physically measured on site and used to characterize the EnergyPlus flow elements. Utility Data is used to estimate the real world internal gains profile. Wind pressure coefficients are calculated with third-party software and implemented into EnergyPlus. These and other data are used to create a fully integrated multizone airflow network energy model. The following sections explain each feature of the energy model in detail.

\subsubsection{Building Model}

The building model of BHB is developed in EnergyPlus in conjunction with DesignBuilder (Tindale 2005). DesignBuilder is a detailed building energy analysis tool that uses EnergyPlus as the simulation engine. DesignBuilder enhances EnergyPlus by providing a 3-dimensional Graphic User Interface (GUI) that allows users to construct the building geometry quickly and easily. A detailed floor plan of BHB is built up in DesignBuilder first, including all partitions, windows, and doors. The geometry model 
exported from DesignBuilder is then continuously modified in EnergyPlus to more closely represent the actual BHB.

Due to the use of certain features in the airflow model and limitations of EnergyPlus, the BHB energy model can only simulate one floor at a time. It is assumed that vertical heat conduction between floors is negligible due to the very small difference in zone temperature. This assumption is tested and validated using CONTAM, a well known multizone airflow and contaminant transport analysis software (G.N. Walton \& Dols 2006), by quantifying the difference in the air flowrate entering a zone due to elevation differences. The heat gain/loss associated with the variation in air flowrate is then compared to the overall heat gain/loss through the zone's envelope and found to be negligible. This suggests that if two zones, one above the other, are controlled by the same algorithm, the temperature difference between them will be very small and heat conduction between them through the floor/ceiling will be nearly zero and therefore can be neglected.

For this reason, the model incorporates exterior roof and floor surfaces that are super-insulated while maintaining the thermal mass associated with each. The result is that the floor and ceiling store thermal energy in a realistic manor, but heat flux from the zone to the exterior through the floor and roof is essentially zero. For example, the BHB's floors are separated by a 0.2 meter thick concrete slab. The floor construction used in the EnergyPlus model is a 0.1 meter thick slab with an artificial no-mass insulation layer on the exterior with an R-value of $100 \mathrm{~m}^{2} \mathrm{~K} / \mathrm{W}$. Half the slab thickness is 
used because it represents the portion of the slab that would store and release thermal energy into the zone in question. The other half of the slab would only interact with the zone below, and therefore it is neglected.

The BHB has a mechanical system serving the corridor zone that maintains the temperature and ventilation requirements. This system is included in the BHB energy model in order to recreate the real-world boundary condition for the dormitory zones. The energy consumed by this system is not analyzed or considered in this study. This system is implemented in the BHB energy model using a unitary HVAC template. The cooling mode setpoint is $24^{\circ} \mathrm{C}$ and the heating mode is $20^{\circ} \mathrm{C}$, on a continuous basis. Each dormitory is outfitted with an electric baseboard heater. Typical zones have 1000-watt capacity while corner zones and zones with multiple exterior walls have 2000-watt capacity. The heaters are implemented in EnergyPlus using the ZoneHVAC:Baseboard:Convective:Electric object.

\subsubsection{On-Site Measurements}

In order to represent the real world boundary conditions as closely as possible, in-situ measurements are used to build the energy model whenever possible. This section details the process of using blower door tests to characterize the typical flow paths, as well as the method of using utility data to estimate the typical internal gains profile. 
A standard blower door test is performed that measures the infiltration leakage area (at 50 Pascals) of one typical (non-corner unit) BHB dormitory that has one exterior wall. A blower door test uses a large fan to induce negative pressure on the zone in question. The Flowrate and pressure drop across the fan is measured and used to estimate the effective leakage area for each external wall in the BHB. The blower door equipment is then used to induce and measure the airflow through an open window as well as the pressure difference across the opening. Tests are conducted at 25,50 , and 75 Pascal pressure differences and then averaged. This allows the area and discharge coefficient to be measured simultaneously. Equation 2, which is developed using the Bernoulli Principle, shows this relationship.

$$
A_{W} C_{d}=10000 Q \sqrt{\frac{\rho_{\text {air }}}{2 \Delta P}}
$$

where $A_{w}$ is the window area $\left(\mathrm{cm}^{2}\right), C_{d}$ is the discharge coefficient (unitless), $Q$ is the volumetric flow rate through the window $\left(\mathrm{m}^{3} / \mathrm{s}\right), \rho_{\text {air }}$ is the density of air $\left(\mathrm{kg} / \mathrm{m}^{3}\right)$, and $\Delta \mathrm{P}$ is the pressure difference $(\mathrm{Pa})$.

This method is advantageous because the window opening area is very difficult to measure accurately without sophisticated equipment; using a tape measure would not provide accurate enough data. In addition, the discharge coefficient of the window assembly is very difficult to measure once installed on the façade and is likely to change with the window position. The quantity $A_{W} C_{d}$ is used as input for the airflow model to calculate the volumetric flow rate through the window. Repeating this process at five 
window positions (closed, $5^{\circ}, 10^{\circ}, 15^{\circ}$, and the maximum $20^{\circ}$ ) characterizes the window across the complete range of opening positions. The results from both the standard and modular window blower door test are summarized in Table 2.

Table 2 Blower Door Test Results

\begin{tabular}{|c|c|c|c|c|c|}
\hline & \multicolumn{5}{|c|}{ Area*Cd at Opening Angle (cm^2) } \\
\hline $\begin{array}{c}\text { Pressure Drop } \\
\text { (pa) }\end{array}$ & $\mathbf{0}$ & $\mathbf{5}$ & $\mathbf{1 0}$ & $\mathbf{1 5}$ & $\mathbf{2 0}$ \\
\hline $\mathbf{2 5}$ & 166 & 565 & 1378 & 2346 & 2947 \\
\hline $\mathbf{5 0}$ & 168 & 518 & 1382 & 2411 & 3370 \\
\hline $\mathbf{7 5}$ & 170 & 508 & 1431 & N/A & N/A \\
\hline Average & $\mathbf{1 6 8}$ & $\mathbf{5 3 0}$ & $\mathbf{1 3 9 7}$ & $\mathbf{2 3 7 9}$ & $\mathbf{3 1 5 9}$ \\
\hline
\end{tabular}

Internal gains are one of the most widely varying parameters associated with occupant behavior. Every occupant's habits and schedule are likely to vary from one to another. Historical power meter data are used in this study to develop an average monthly consumption profile. It is assumed that $100 \%$ of the electrical energy consumed is emitted into the dormitory as internal gains.

Every dormitory has a small refrigerator that cycles continuously. This internal gain is implemented in EnergyPlus using an ElectricalEquipment object and is not dependent on occupancy. After subtracting the refrigerator's load from average monthly profile, the remaining internal gains such as plug loads and lighting are implemented in EnergyPlus using the Lights object and correspond to the occupancy 
schedule. An occupancy schedule for a university bedroom, developed by the UK National Calculation Method, is adopted in this study to represent the number of occupants at any given time of day (NCM 2009)

\subsubsection{Airflow Network Model}

A multizone airflow network model is developed in EnergyPlus that includes all airflow paths, such as doors, windows, exhaust fans, and effective leakage areas (ELAs). The multizone model calculates airflow based on the pressure-flow characteristics of each flow path. The airflow network model is verified by intermodal comparison with CONTAM by comparing the flowrate calculated by each program while under identical conditions. The important components of the multizone airflow model include the infiltration model of the dormitory, the operable window model, the bathroom exhaust fans, the pressurized hallway zone, and the wind pressure coefficient (to be addressed in the following section).

The dormitory infiltration is modeled using an AirflowNetwork:MultiZone:Surface:EffectiveLeakageArea object in EnergyPlus. The measured ELA value and reference pressure at which the blower door test is conducted (shown in Table 2) are used to calculate infiltration flow rate of each typical dormitory. The ELA value of corner dormitories with more than one exterior wall is estimated based on the measurement of the typical room but proportionally adjusted to reflect increased infiltration due to larger exterior façade area. The door that connects each dormitory to 
the corridor is modeled using the equivalent of the ASHRAE best estimate for a single, not weather-stripped, internal door (ASHRAE 1997). The operable window is modeled using the AirflowNetwork:Multizone:Surface:DetailedOpening object in EnergyPlus. It allows users to specify opening area and discharge coefficient data at up to four different opening positions indicated by opening factor.

Another important characteristic of the BHB's hybrid system is that the HVAC system in the corridor supplies the make-up air that is extracted by the exhaust fans installed in the bathroom of each dormitory. This results in a positive pressure in the corridor zone relative to individual dormitories and influences the inter-zonal flow through door cracks. Since the corridor is mechanically conditioned, this air exchange will also bring certain amount of cooling to the dormitory and is important to capture in detail in the airflow model. The bathroom exhaust fan in each dormitory is modeled using the ZoneExhaustFan object in EnergyPlus, and the exhaust airflow is assumed to be $0.0094 \mathrm{~m}^{3} / \mathrm{s}$ (20 CFM) according to ASHRAE 62.1-2004 guidelines (ASHRAE 2004a). The positive pressure in the common corridor is modeled by adding leakage in the return duct using the AirflowNetwork:Distribution:Component:LeakageRatio object in EnergyPlus. The leakage ratio is adjusted so that the surplus air (i.e. the difference between supplied air and returned air) of the corridor zone is equal to the number of exhaust fans multiplied with the continuous flowrate of $0.0094 \mathrm{~m}^{3} / \mathrm{s}(20 \mathrm{CFM})$. 


\subsubsection{Wind Pressure Coefficients}

Wind pressure is one of the most important boundary conditions in natural ventilation modeling. It is also very difficult to predict for buildings with complicated shapes located in dense urban environments. Equation 3 shows the wind pressure model used in EnergyPlus. The challenging issue is to determine the wind pressure coefficients along the length and height of the external façade.

$$
p_{\text {wind }}=C_{p} \rho \frac{V_{r e f}^{2}}{2}
$$

where, $p_{w i n d}$ is the wind pressure exerted on a surface, $C_{p}$ is the dimensionless wind pressure coefficient, $\rho$ is the density of the airstream, and $V_{\text {ref }}$ is the wind velocity.

As an alternative to developing a full Computational Fluid model or conducting wind tunnel experiments, an application external to EnergyPlus is used to estimate the wind pressure coefficients along the building's exterior surface. This program, called $\mathrm{Cp}$ Generator (Knoll et al. 1995), uses specially developed algorithms based on systematically performed wind tunnel tests and published results of on-site tests to predict wind pressure coefficients. It has been validated by several different research projects over the course of 20 years (Costola et al. 2009). Cp Generator also accounts for wind shielding by local obstacles, which makes it particularly useful for the BHB case, since it is located in a dense urban environment.

Figure 7 shows a map of the BHB's neighborhood. Buildings that fall within the suggested radius of 5 times the BHB's height are included as obstacles in the $\mathrm{Cp}$ 
Generator model. The $C_{p}$ values at each external node of the BHB, namely each window and external wall, are estimated by the $\mathrm{Cp}$ Generator simulation in 10-degree increments. Figure 8 shows sample wind pressure coefficients at the center of each façade on the west wing of the BHB. The wind direction is measured clockwise from the North.

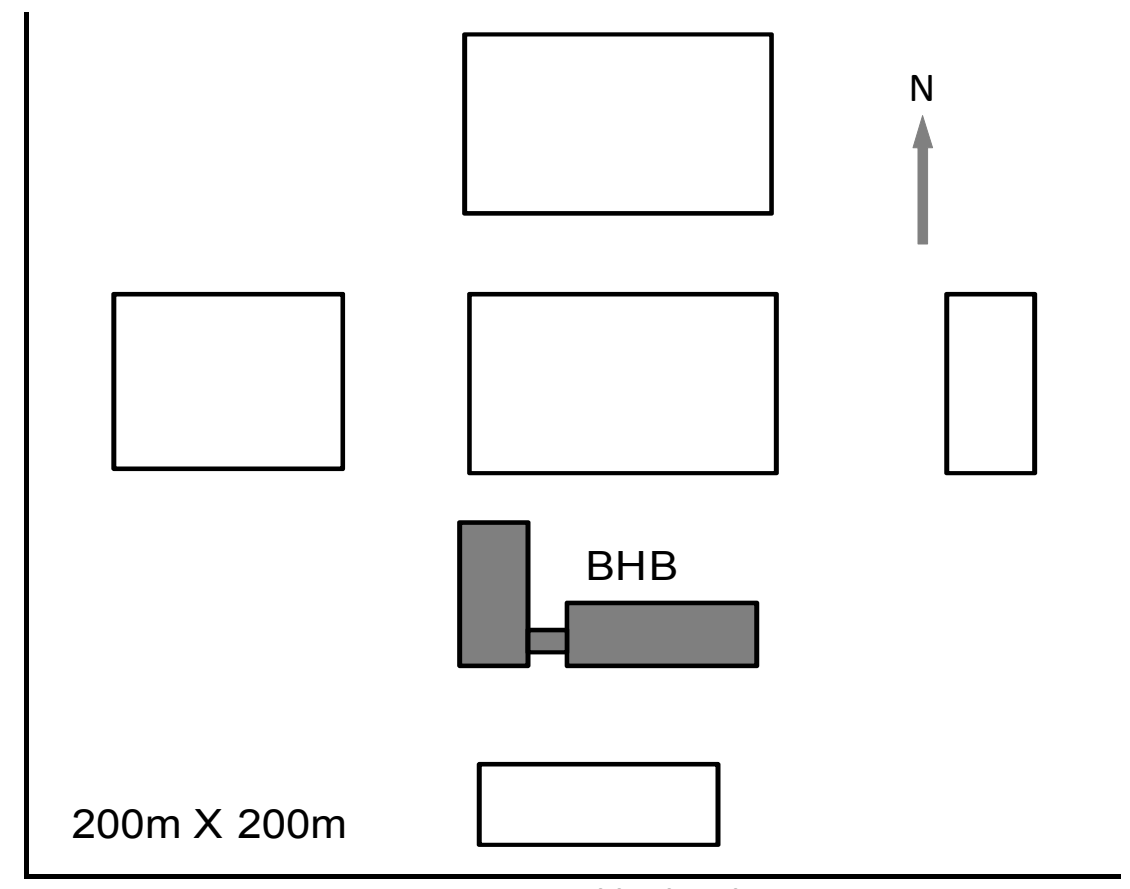

Figure 7 - BHB Neighborhood Map 


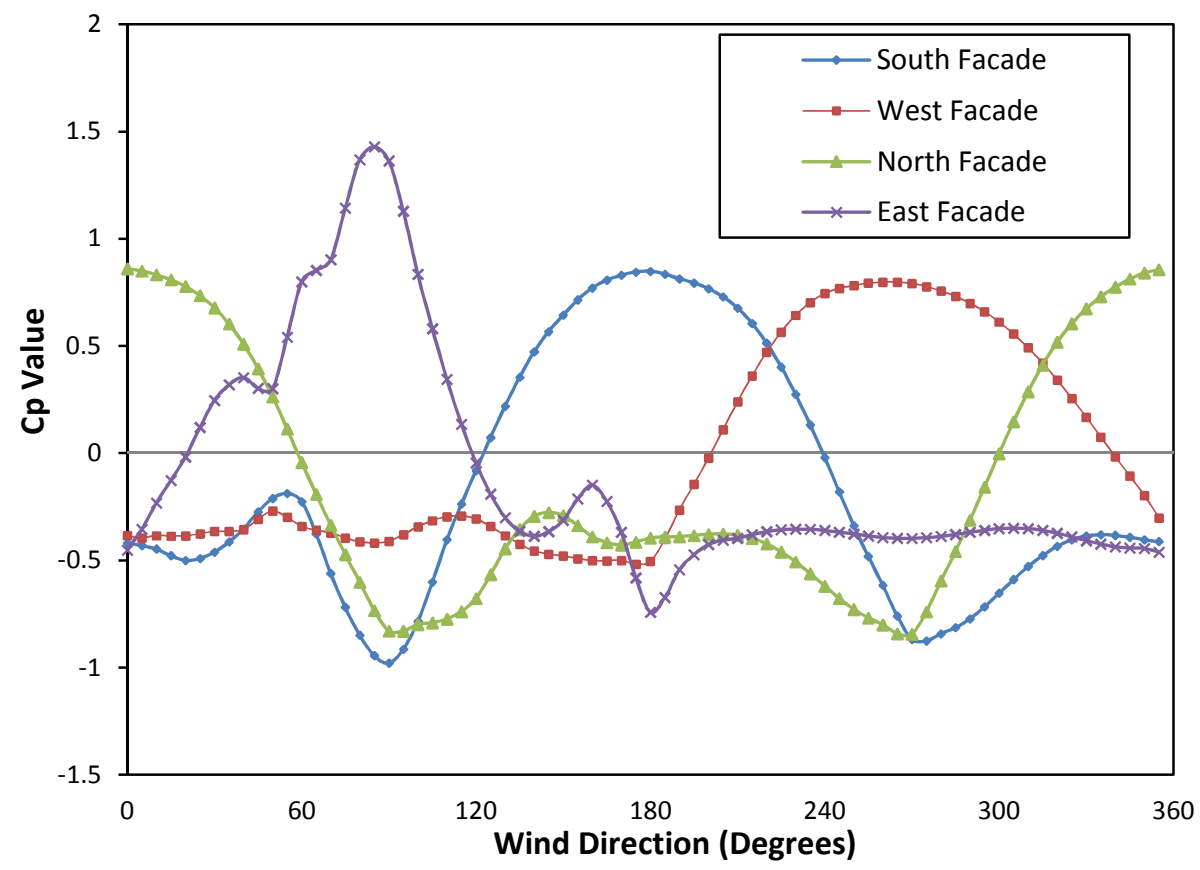

Figure 8 Sample Wind Pressure Coefficient Output from $\mathrm{Cp}$ Generator 


\subsection{Baseline Discretized Temperature Control Algorithm}

The baseline control algorithm considered for this study is a modification of the algorithm built into EnergyPlus. This temperature-based (TB) algorithm determines the window opening factor (a value between 0 and 1 , which is multiplied by the area available for venting) based on the difference between the indoor and outdoor temperature. The algorithm is based on two temperature difference limits. The lower limit defines the point below which the opening factor stays constant at 1 (i.e. window

stays at the maximum opening). The upper limit is the point beyond which the opening factor is 0 (i.e. window stays closed). Opening factors at other temperature difference points between the two limits are calculated by linear interpolation. This algorithm is implemented in EnergyPlus as a continuous function, meaning there are an infinite number of possible opening positions. For this study, this same algorithm is discretized into five possible opening positions. These are the same opening positions used for the blower door tests (discussed in section 3.2.2). This is done to reduce the number of possible control decisions and to be able to make a reasonable comparison with the custom designed controller, which will be discussed in the following section.

Figure 9 shows a graphical representation of the algorithm. The upper plot is a screenshot from the EnergyPlus Documentation. The lower plot shows two curves. The continuous algorithm curve is laid over the discretized curve, showing how the control process is broken into five possible window positions. The maximum opening factor of 0.3273 corresponds to a wide-open window. A parametric analysis is performed in 
EnergyPlus to determine what the temperature limits result in the fewest number of over-heated degree-hours during the summer months, resulting in a lower limit of $5^{\circ} \mathrm{C}$ and upper limit of $20^{\circ} \mathrm{C}$ for this study. The discretized algorithm is implemented in EnergyPlus using the BCVTB program (Wetter \& Haves 2008). This process will be described in detail in the next section.
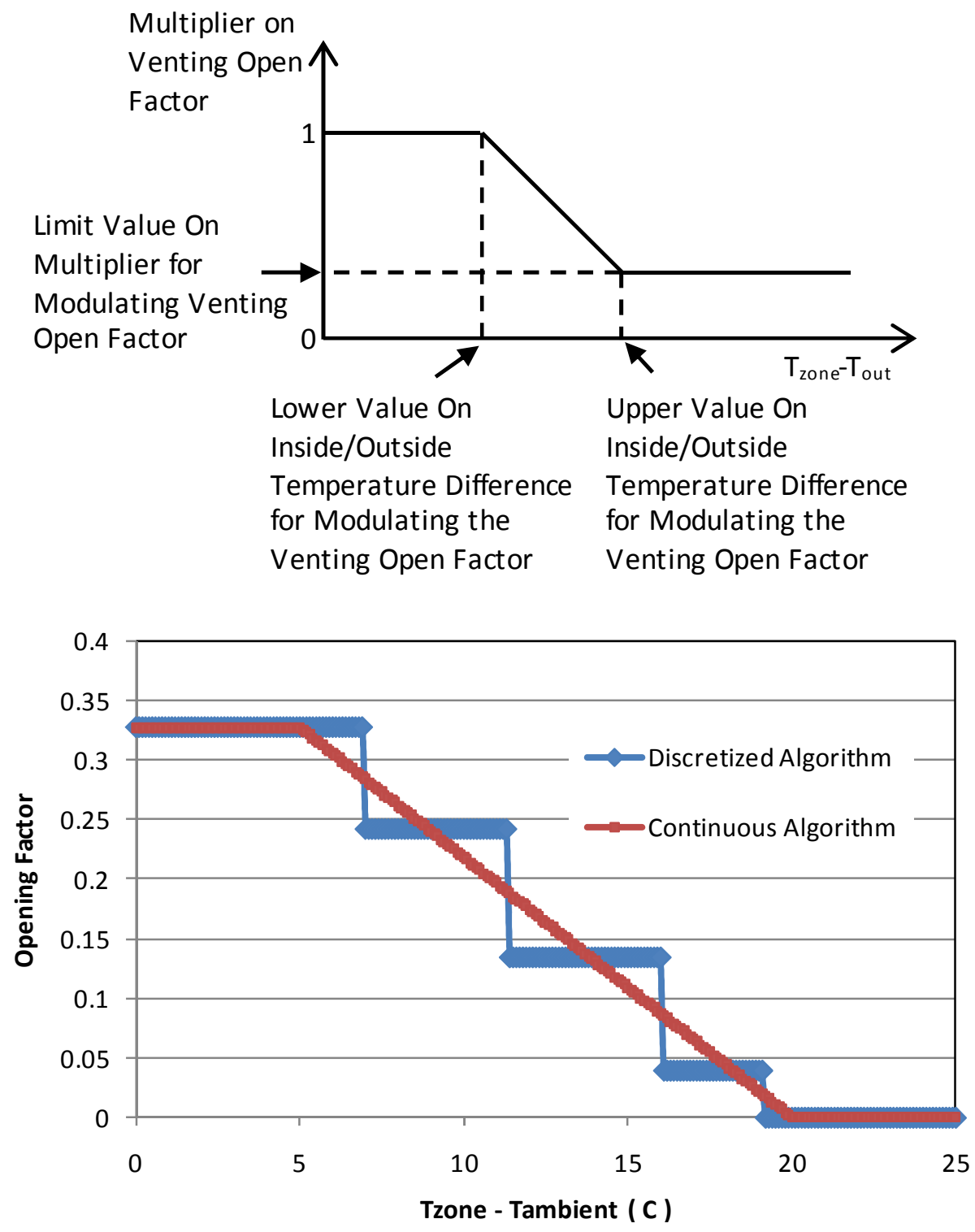

Figure 9 - Temperature Control Algorithm 


\subsection{Baseline Energy Model}

The baseline energy model established for the energy comparison is identical model detailed in Model Development section (3.2) except the zone baseboard heaters are removed and an IdealLoadsAirSystem is added to the entire building, serving all zones. The windows are kept closed for the entire yearlong simulation, but the airflow network still calculates infiltration flow through cracks in exterior walls. The ideal load system simply calculates the heating and cooling load, in watts, for each zone at each time-step. In post-processing, the electrical energy needed to heat outdoor air (30 CFM for ventilation plus 20 CFM for bathroom exhaust per zone) to the space at room temperature is calculated, as well as the fan energy needed to move the air. Then a coefficient of performance of 1.5 for heating mode and 2.75 for cooling mode is applied to the ideal load, which represents typical values for an electric based heat pump system (RETScreen 2005). The heating setpoint of $20^{\circ} \mathrm{C}$ is consistent between all models, and the ideal system model uses a cooling setpoint of $24^{\circ} \mathrm{C}$. Fan energy is calculated to be $20 \mathrm{HP}$, which is based on the required flowrate and estimated static pressure. The energy consumption of this system will be compared with the controller described in Chapter 4. 


\section{Custom Model-based Controller Development}

This chapter details the development of a custom model-based predictor that estimates natural ventilation flowrate and temperature response for a set of window positions for each zone in the BHB. In addition, two logic controllers are described, which select the most appropriate window position to provide adequate ventilation and desired thermal comfort. The model-based (MB) controller developed for this study is referred to as "custom designed" because it relies on a database of unique zone information. Populating this database requires intimate knowledge of the building's construction, as well as significant effort to determine the wind pressure coefficient, $C_{p}$, at each operable window and the ELA of building envelope.

\subsection{Development of a Model-based Predictor}

The basic function of a MB predictor is to first estimate the outdoor air volume likely to enter the zone at each of the five window positions (closed, $5^{\circ}, 10^{\circ}, 15^{\circ}$, and the maximum $20^{\circ}$ ). Then, the zone energy balance is solved to determine the corresponding zone temperature response. Finally, the logic controller determines the appropriate window opening position based on preset performance criteria in ventilation and thermal comfort. The flowchart in Figure 10 describes this process.

Single-sided ventilation, which occurs in all dormitories with a single opening, can be estimated using Equation 4. This method is a simplified representation of the actual phenomenon of single-sided airflow, but it captures the effect from the most 
influential driving forces. These equations have been verified and utilized in previous studies on single-sided natural ventilation (Larsen \& Heiselberg 2008), (W. De Gids \& H. Phaff 1982), and (Allocca et al. 2003). The equation has a multiplier of 0.5 because approximately half of the opening allows incoming flow, while the other half lets air out of the zone.

$$
\dot{\boldsymbol{m}}_{\text {OA }}=\frac{1}{2}\left(A C_{d}\right) \boldsymbol{\rho} \sqrt{\frac{2}{\rho}\left(\Delta \boldsymbol{P}_{\text {stack }}+\Delta \boldsymbol{P}_{\text {wind }}+\Delta \boldsymbol{P}_{H V A C}\right)}
$$

Where $\dot{m}_{O A}$ is the outside air mass flow rate, $\rho$ is the density of air, the quantity of $\left(A^{*} C d\right)$ is measured during the blower door tests for the five opening positions. The individual $\Delta P$ terms are detailed in Equations 5-7.

$$
\Delta \boldsymbol{P}_{\text {stack }}=\frac{\rho g}{2} \frac{\left(T_{\text {zone }, t-1}-T_{\text {amb }}\right) H_{\text {window }}}{\bar{T}}
$$

Where $\rho$ is the density of air, $g$ is gravitational acceleration, $T_{z o n e, t-1}$ is the zone temperature from the previous timestep, $T_{a m b}$ is the outdoor temperature, $H_{\text {window }}$ is the opening height of the window, and $\bar{T}$ is the average of zone and outdoor temperature.

$$
\Delta P_{\text {wind }}=\frac{C_{p} V_{\text {wind }}^{2} \rho}{2}
$$

Where $C_{p}$ is the wind pressure coefficient, $V_{\text {wind }}$ is the wind velocity, and $\rho$ is the density of air.

$$
\triangle P_{H V A C}=4 P a
$$

The zone energy balance is solved using an explicit method, where the future zone temperature is estimated based on the temperature from the previous time-step 
as shown in Equation 8. The zone energy balance equation is solved with the window opened at each of the five window positions, and then the five projected zone temperatures are sent to the logic controller, where the most appropriate window position is chosen based on the preset control objective (i.e. the performance criteria). This logic system will be described in section 4.3.

$$
T_{\text {zone }, t}=T_{\text {zone,t-1 }}+\frac{\left(Q_{\text {natvent }}+Q_{\text {conduction }}+Q_{\text {solar }}+Q_{\text {internal gains }}\right)}{M_{\text {thermal }} C_{p, a i r}} \Delta t
$$

Where $T_{z o n e, t}$ is the zone temperature calculated at the current timestep, $T_{z o n e, t-1}$ is the zone temperature from the previous timestep, $\Delta t$ is the timestep length, $M_{\text {thermal }}$ represents the thermal mass of the zone, and $C_{p \text {,air }}$ is the heat capacity of air. The individual terms $Q$ are detailed in Equations 9-12.

$$
Q_{\text {natvent }}=\dot{m}_{O A} C_{p, a i r}\left(T_{a m b}-T_{z o n e, t-1}\right)
$$

Where $Q_{\text {natvent }}$ is the energy add to or removed from the zone from natural ventilation flow, $\dot{m}_{O A}$ is the outside air mass flow rate, $C_{p \text {,air }}$ is the heat capacity of air

$$
Q_{\text {conduction }}=U A_{\text {wall }}\left(T_{a m b}-T_{\text {zone }, t-1}\right)
$$

Where $Q_{\text {conduction }}$ is the energy add to or removed from the zone from conduction heat transfer.

$$
Q_{\text {solar }}=A_{\text {window }} \operatorname{SHGC}\left(Q_{\text {solar,beam }}+Q_{\text {solar, difuse }}\right)
$$

Where $Q_{\text {solar }}$ is the energy add to the zone from solar radiation incident on the zone windows, $S H G C$ is the solar heat gain coefficient of the window, $A_{\text {window }}$ is the total glass area, and $Q_{\text {solar,beam }}$ and $Q_{\text {solar,difuse }}$ are the two components of solar radiation. 


$$
\boldsymbol{Q}_{\text {internal gains }}=\boldsymbol{Q}_{\text {people }}+\boldsymbol{Q}_{\text {lights }}+\boldsymbol{Q}_{\text {equipment }}
$$

Where $Q_{\text {internal gains }}$ is the energy added to the zone from people, lights, and electrical equipment.

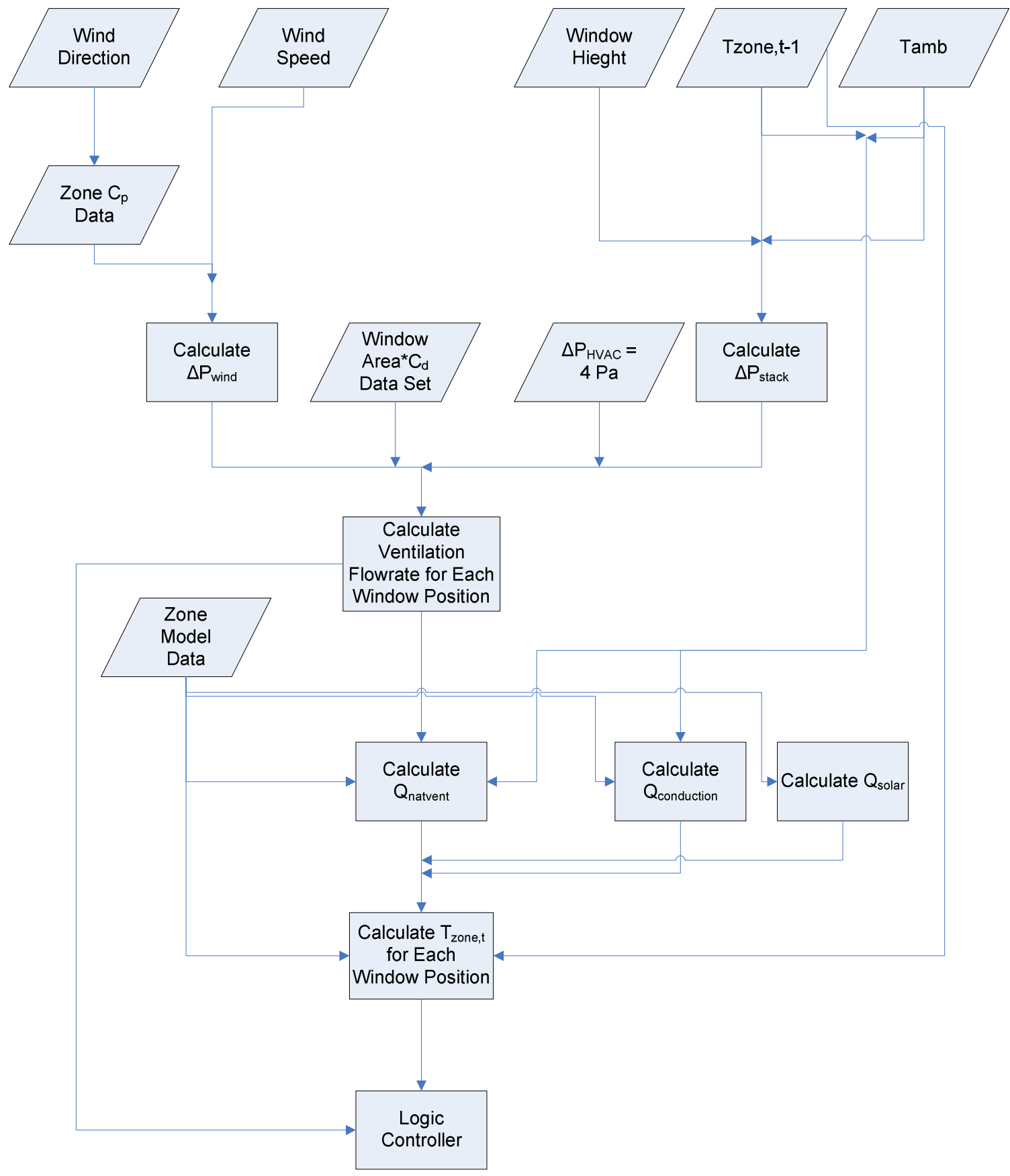

Figure 10 Data Flow for Model-Based Controller 


\subsection{Predictor Analysis and Correction}

This section addresses the steps taken to further enhance the performance of the MB predictor proposed in section 4.1. Early simulation results reveal the ventilation rates predicted by the method described in section 4.1 are consistently inaccurate when compared with the actual flowrate output from EnergyPlus (which is calculated with a much more complex internal algorithm). This inaccuracy results in an incorrect decision on window opening position, and leads poor ventilation and thermal comfort performance. By comparing the predicted and actual flowrate, a linear correction factor is developed for each opening position. Figure 11 shows an example of this process for two of the five window positions. The slope of the linear trendline is used as the correction factor, which is applied to the MB predictor proposed earlier. Each window position is analyzed independently, and therefore has a unique correction factor. Table 3 summarizes the correction factor for each window position.

Table 3 Predicted Flowrate Correction Factors

\begin{tabular}{|c|c|c|}
\hline $\begin{array}{c}\text { Window } \\
\text { Position }\end{array}$ & $\begin{array}{c}\text { Correction } \\
\text { factor }\end{array}$ & $\begin{array}{c}\mathbf{R}^{\mathbf{2}} \\
\text { Value }\end{array}$ \\
\hline 0 (closed) & 0.5247 & 0.8675 \\
\hline $1\left(5^{\circ}\right)$ & 0.6513 & 0.7702 \\
\hline $2\left(10^{\circ}\right)$ & 0.7342 & 0.8076 \\
\hline $3\left(15^{\circ}\right)$ & 0.9400 & 0.7293 \\
\hline $4\left(20^{\circ}\right)$ & 1.2493 & 0.8414 \\
\hline
\end{tabular}




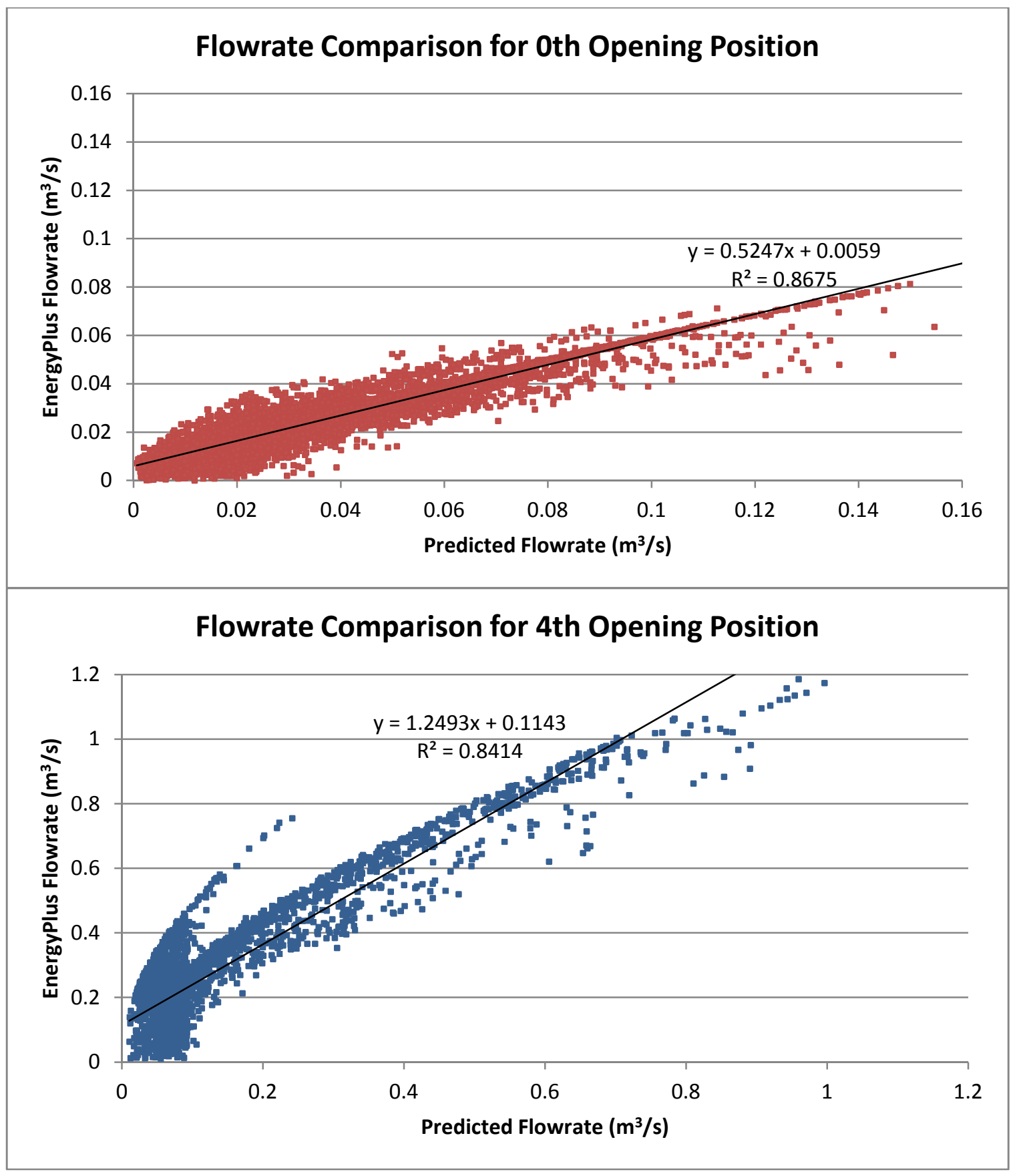

Figure 11 Comparison of Actual Flowrate and Predicted Flowrate 


\subsection{Control Logic and Parameterization of $\mathrm{C}_{\mathrm{p}} * \mathrm{~V}^{2}$}

This section introduces the control algorithm developed and implemented in the logic controller. The basic function of the logic controller is to determine the most appropriate opening position for the operable window in each dormitory zone, based on the predicted zone temperatures and ventilations rate from the MB predictor. As an example, if , according to the MB predictor, fully opening the window for the timestep in question will result in the zone temperature dropping below the acceptable minimum, the controller will reduce the window opening area to help prevent this.

In general, there are two operating modes for the MB controller: maximum cooling mode and minimum ventilation mode. The maximum cooling mode is used during the summer months. When the outdoor air temperature is lower than the zone temperature this mode is used to passively cool the living spaces. In this scenario, the MB controller will actively control window opening to lower the zone temperature as much as possible without dropping below the minimum acceptable indoor temperature specified in Figure 4.

When the outdoor temperature is higher than the zone temperature or when the zone is cooler than the acceptable minimum, the minimum ventilation mode is used. In this mode, the controller adjusts the window position to maintain the ventilation rate as closely as possible to $0.0142 \mathrm{~m}^{3} / \mathrm{s}$ (30 CFM). By minimizing the incoming outdoor air when conditions are unfavorable, the controller attempts to minimize the cooling load due to over-heating when the outdoor temperature is too high, and reduce the heating 
load due to over-cooling when outdoor temperature is too low. Figure 12 shows a flowchart of the control logic.

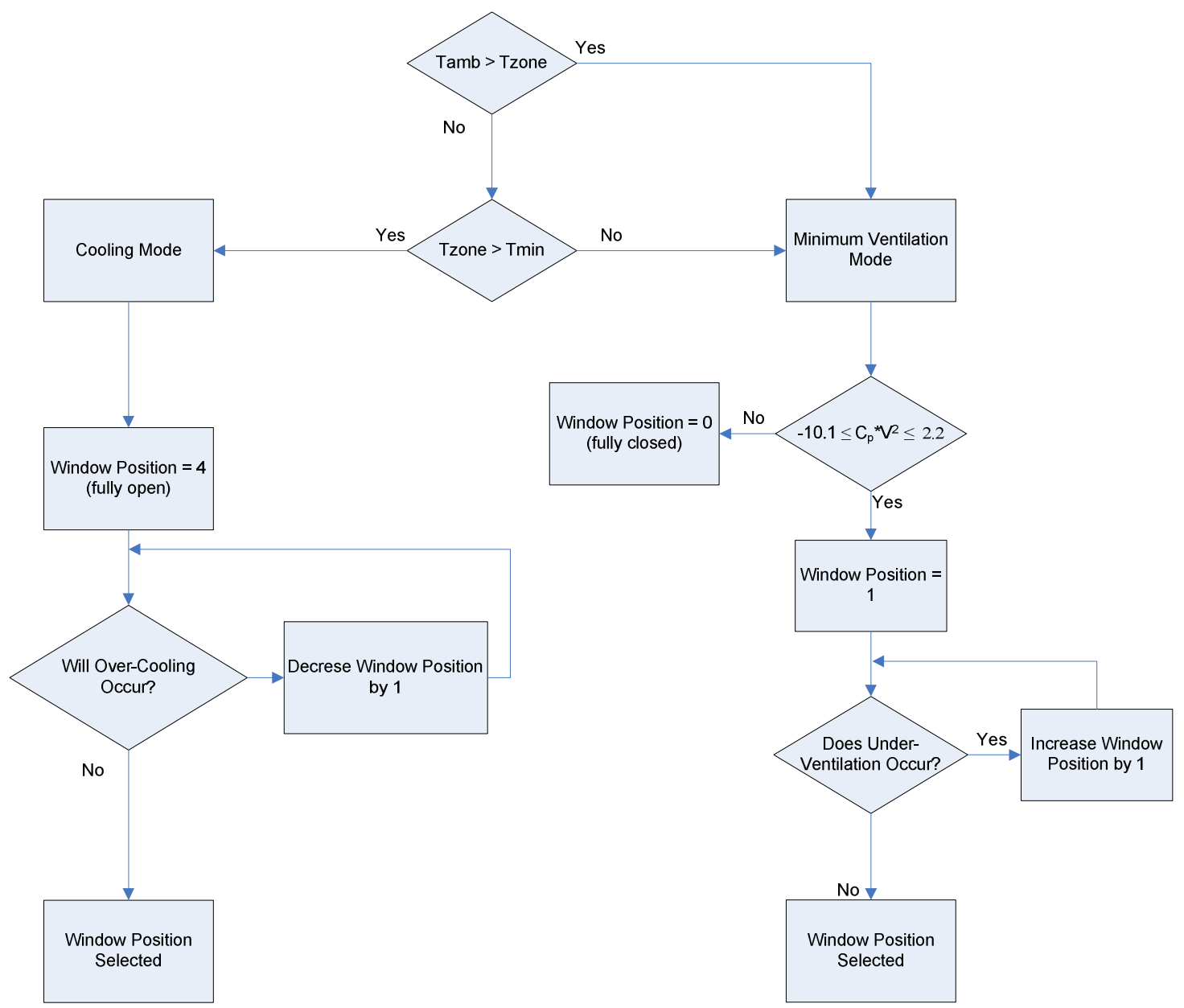

Figure 12 Model-Based Control Logic Flowchart

When operating in minimum ventilation mode, simulation results show that minimum ventilation can be achieved through infiltration alone without opening windows for a large number of hours. Statistical analysis indicates that there is a strong correlation between combination of wind direction and speed and the ability of infiltration alone providing sufficient ventilation. The combined effect of wind direction 
and speed is parameterized in this study by multiplying the zone wind pressure coefficient $\left(C_{p}\right)$ by the square of wind velocity $\left(V^{2}\right.$ wind $)$.

A yearlong EnergyPlus simulation is performed with all the windows in the BHB closed. The resulting zone ventilation rates for all dormitory zones are divided in two categories: properly ventilated and under-ventilated. Then the quantity $\left(C_{p} * V^{2}\right.$ wind $)$ for each flowrate is compared between the two groups of properly ventilated and underventilated. Figure 13 shows the histograms of $\left(C_{p} * V^{2}{ }_{\text {wind }}\right)$ for both groups. The two groups are nearly complimentary except over a small overlapped region. The majority of under-ventilation occurs when the absolute value of $\left(C_{p} * V^{2}\right.$ wind $)$ is near zero, while the majority of proper ventilation occurs further away from zero. A simple t-test between the two populations shows that they are significantly different.

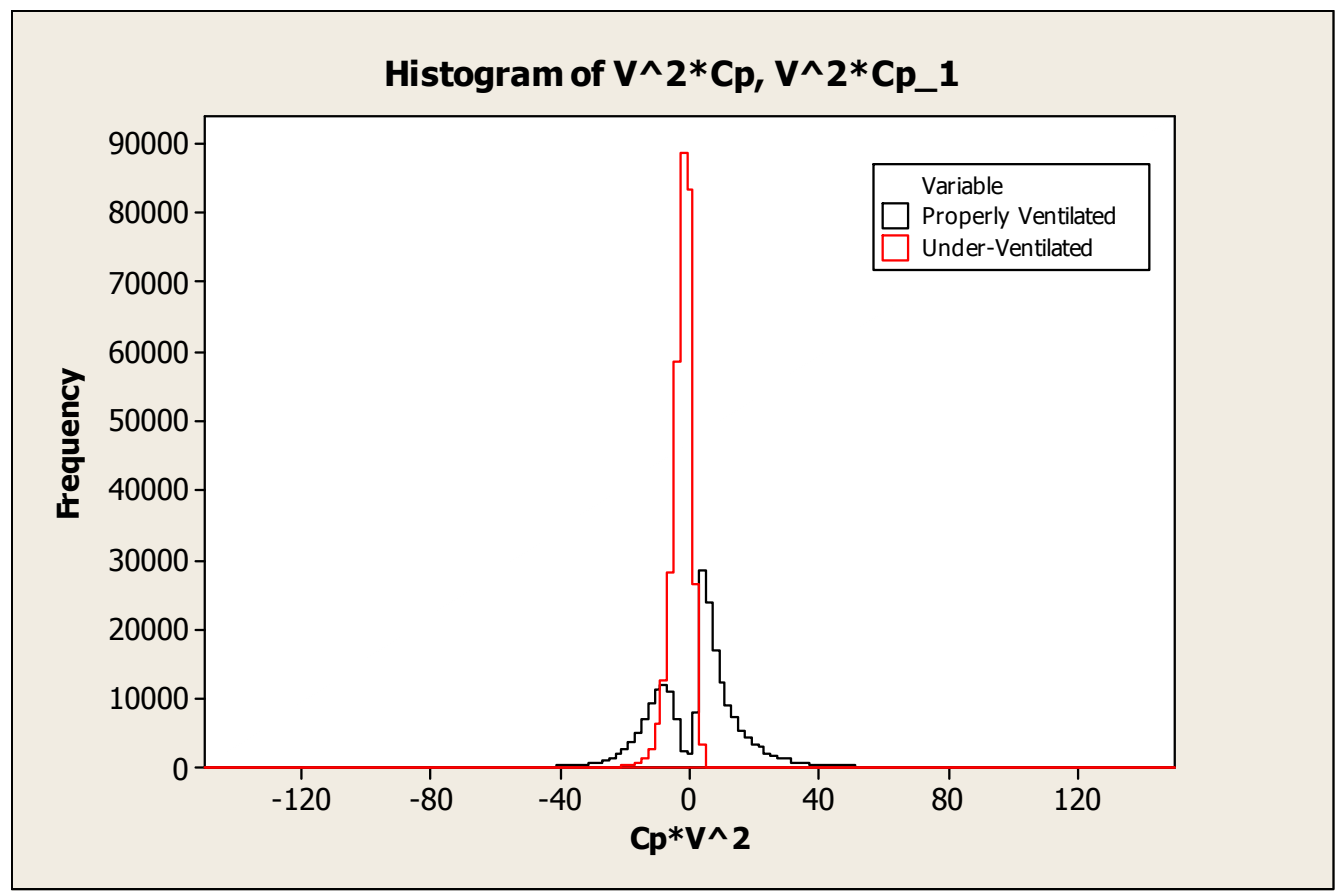

Figure 13 Distribution of Ventilation Flowrates 
In order to determine the optimum threshold values for $\left(C_{p} * V^{2}\right.$ wind $)$, a Weibull curve is fit to the under-ventilated data, as shown in Figure 14. A Weibull distribution is chosen because it fits the data more accurately than a normal distribution. It should be noted that a Weibull distribution cannot contain negative values, so 200 is added to the quantity $\left(C_{p} * V^{2}\right.$ wind $)$ to ensure all data points are positive. The resulting Weibull curve is plotted in Figure 15 with a $2.5 \%$ threshold value shown in each tail. Once the threshold values are obtained, 200 is subtracted from them to correct for the adjustments. The resulting threshold values for $\left(C_{p} * V^{2}\right.$ wind $)$ are -10.1 and 2.2. This suggests that for a given zone in minimum ventilation mode, the window needs to be opened to meet the minimum ventilation when $\left(C_{p} * V^{2}\right.$ wind $)$ lies between -10.1 and 2.2. If $\left(C_{p} * V^{2}\right.$ wind $)$ falls outside of the range of -10.1 and 2.2 , the ventilation requirement will be met through infiltration alone and the window is closed. 


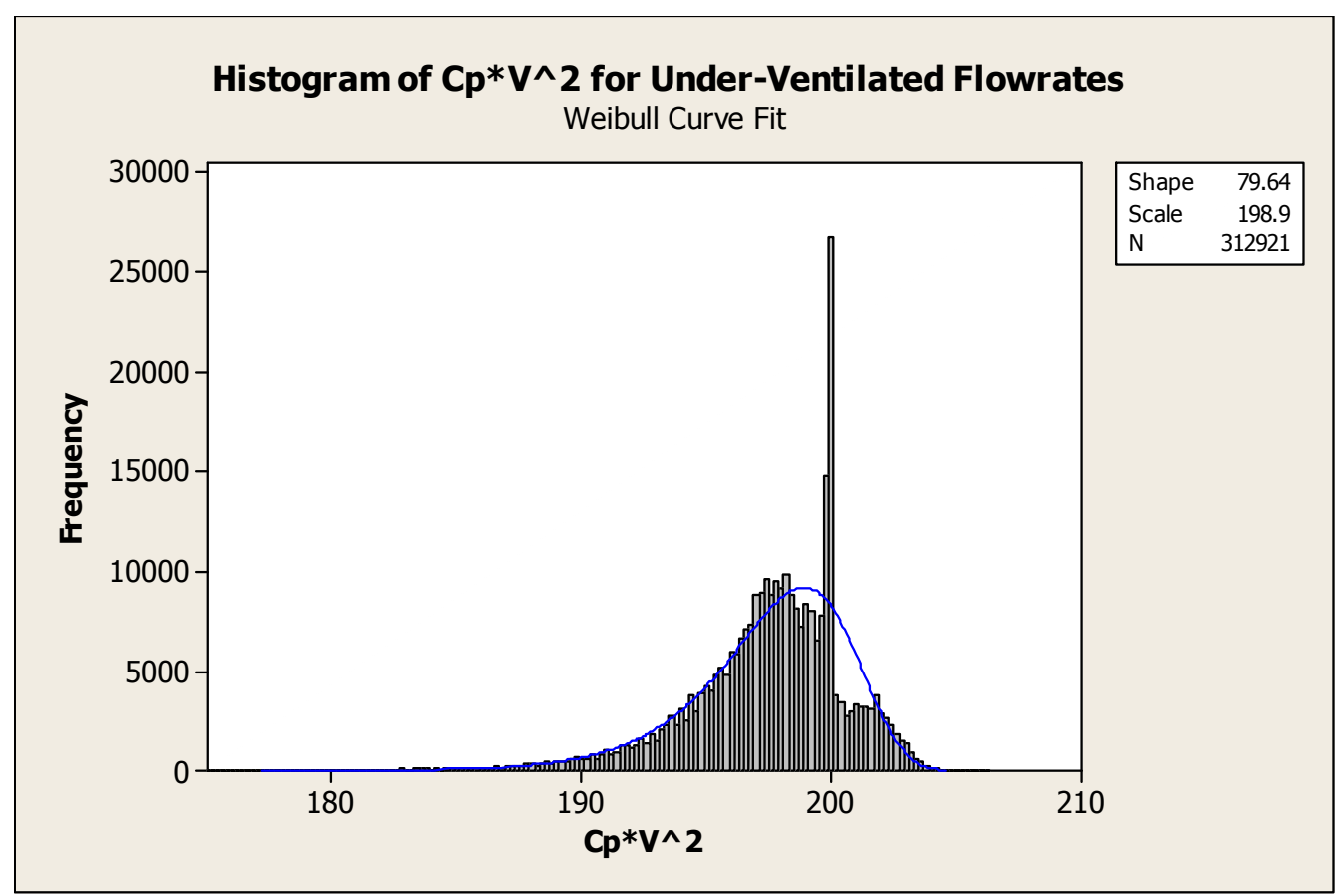

Figure 14 Weibull Curve Fit to Under-Ventilated Flowrates

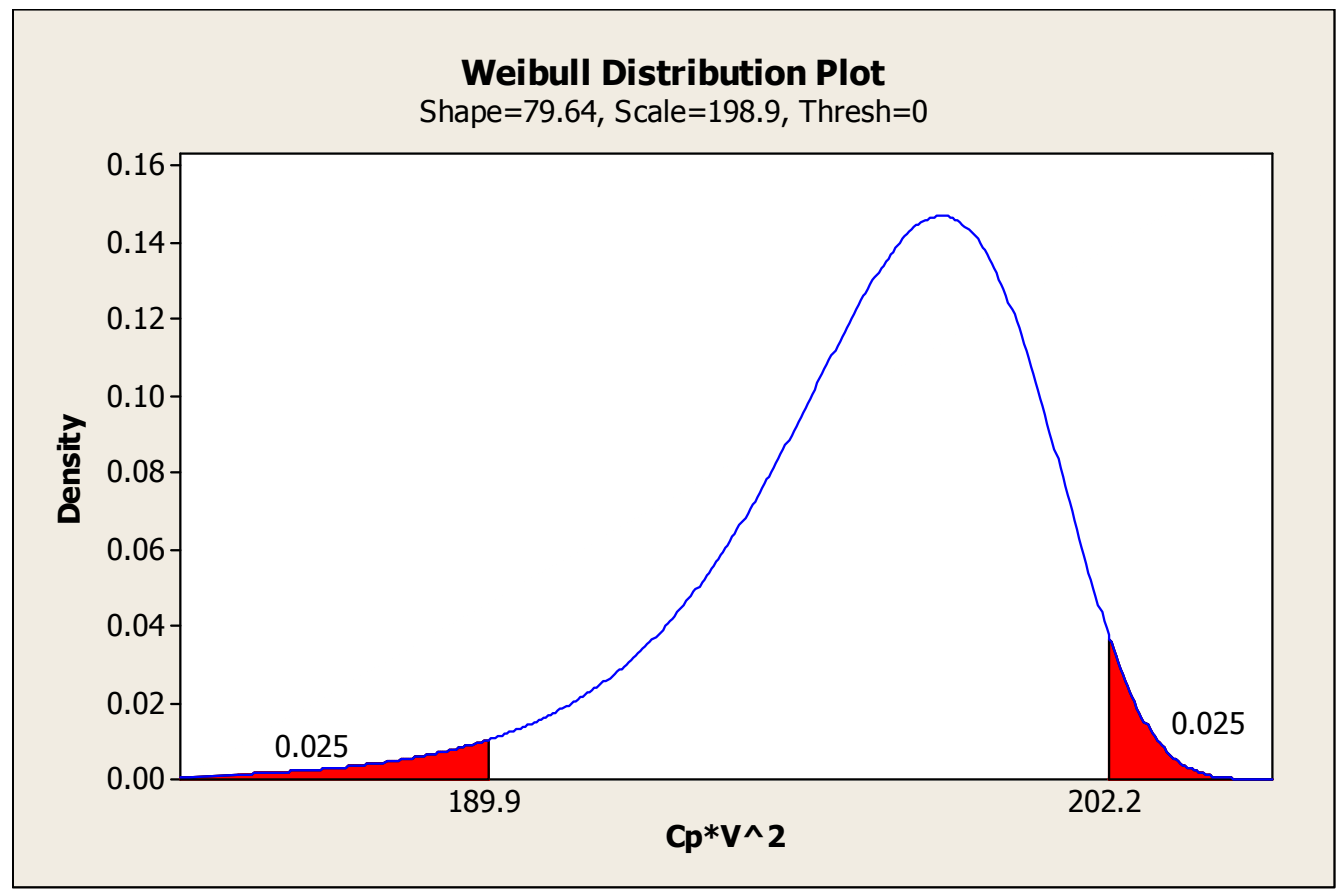

Figure 15 Weibull Curve with 5\% Probability Threshold 


\subsection{Corner Zones}

Each floor of the BHB has four zones on the corner of the building that have two windows located on perpendicular facades. This arrangement creates what is known as cross-flow ventilation, which is significantly different from single-sided ventilation occurring in a typical dormitory with only one window. Cross-flow ventilation occurs when one window allows air to enter the zone, while the other window provides the air exit path. The wind speed and the difference between the $C_{p}$ values of the two windows are the primary driving forces for cross-flow ventilation. Equations $13-15$ describe how the ventilation rate is calculated for cross-flow ventilation (Evola \& Popov 2006), (Allard \& Santamouris 1998)

$$
\dot{m}_{C V}=\rho\left(A_{e f f} C_{d}\right) V_{w i n d} \sqrt{\Delta C_{p}}
$$

Where $\dot{m}_{C V}$ is the air mass flow rate for cross-flow ventilation, the quantity $\left(A_{e f f} C_{d}\right)$ is calculated using Equation 14, $V_{\text {wind }}$ is the wind velocity, and $\Delta C_{p}$ is calculated using Equation 15.

$$
\frac{1}{\left(A_{e f f} C_{d}\right)^{2}}=\frac{1}{\left(A_{i n} C_{d}\right)^{2}}+\frac{1}{\left(A_{o u t} C_{d}\right)^{2}}
$$

Where $A_{e f f}$ is the effective opening area, $A_{\text {in }}$ is the area of the windward window, and $A_{\text {out }}$ is the area of the leeward window.

$$
\Delta C_{p}=C_{p, \text { in }}-C_{p, o u t}
$$

Where $\Delta C_{p}$ is the difference between in the $C_{p}$ values for the windward window, $C_{p, \text { in }}$, and the leeward window, $C_{p, o u t}$. 
Other than the difference in airflow rate calculation, the MB algorithm determines window position for the corner rooms in the same manner as for the typical rooms. The zone temperature is estimated for all five opening positions and the logic controller selects the most appropriate one. It should be noted that the controller does not allow for different opening positions between the two windows. In other words, the two windows in a corner zone are always in the same position. Though this control method may not be ideal, the BHB has only four corner zones per floor. Thus, effort is focused on typical dormitory rooms, which only have one operable window. 


\section{Results}

This chapter presents simulation results on natural ventilation performance of BHB with control algorithms proposed in Chapter 3 and 4 . These control algorithms modulate the opening position of the operable window(s) in each student dormitory independently with the goal of maintaining the thermal comfort and ventilation requirement. The shift of weather pattern between the summer and winter months necessitates the two control modes (i.e. the maximum cooling mode and minimum ventilation mode) introduced in section 4.3 , therefore this chapter presents results analysis of natural ventilation performances in summer and winter independently.

For the sake of brevity, only the $7^{\text {th }}$ floor (the middle of the dormitory floors) of the BHB is analyzed and discussed in detail. Performance statistics for the entire building, floor by floor, are summarized in section 5.4. It is assumed that the $7^{\text {th }}$ floor is representative of the all the other floors. While the performance between different floors is expected to vary slightly due to the variation in $C_{p}$ values with height above the ground, the overall pattern of behavior is the same.

\subsection{Summer Performance Results}

\subsubsection{Summer Ventilation Performance}

This section presents a comparison of ventilation performance by two proposed controllers, namely the TB controller and the MB controller compensated by a 
correction factor, over the extended summer season (June through September). Figure 16 shows a snapshot from a typical summer day of window opening factor, zone temperature, and ambient temperature for BHB unit 11. For both controllers, the day begins at midnight with the window wide open, facilitating night cooling. Shortly thereafter, the TB controller closes the window to the third opening position as the outdoor temperature rapidly drops. When the zone temperature drops below $22^{\circ} \mathrm{C}$, the window closes to prevent over-cooling. The window position then oscillates between fully open and fully closed as the zone temperature cycles around $22^{\circ} \mathrm{C}$. As the outdoor temperature rises, the difference between zone and outdoor temperature becomes less than $5^{\circ} \mathrm{C}$, and the $\mathrm{TB}$ controller opens the window fully. It then remains open until the outdoor temperature rises above the zone temperature, at which point the window is closed. It remains closed until the outdoor temperature falls below the zone temperature again.

The MB controller produces nearly the same operation pattern, but ventilation is prioritized ahead of thermal comfort. When the zone falls below $22^{\circ} \mathrm{C}$, the $\mathrm{MB}$ algorithm determines whether infiltration alone can meet minimum ventilation requirement. If so, the window stays closed. Otherwise, the window will be opened to the position that produces a flowrate closest to the minimum rate.

The notable difference between the two controllers can be observed during the middle of the day, when the outdoor temperature is well above the zone temperature, as shown in Figure 16. Because the TB algorithm fully closes the window during the 
unfavorable outdoor conditions, the zone is under-ventilated for 4.25 hours over the course of this typical day. The MB algorithm only results in 1.5 hours over the same period. The penalty paid in thermal comfort is hardly noticeable; for the MB controlled zone, the peak temperature is $0.09^{\circ} \mathrm{C}$ higher than the TB controlled zone. 


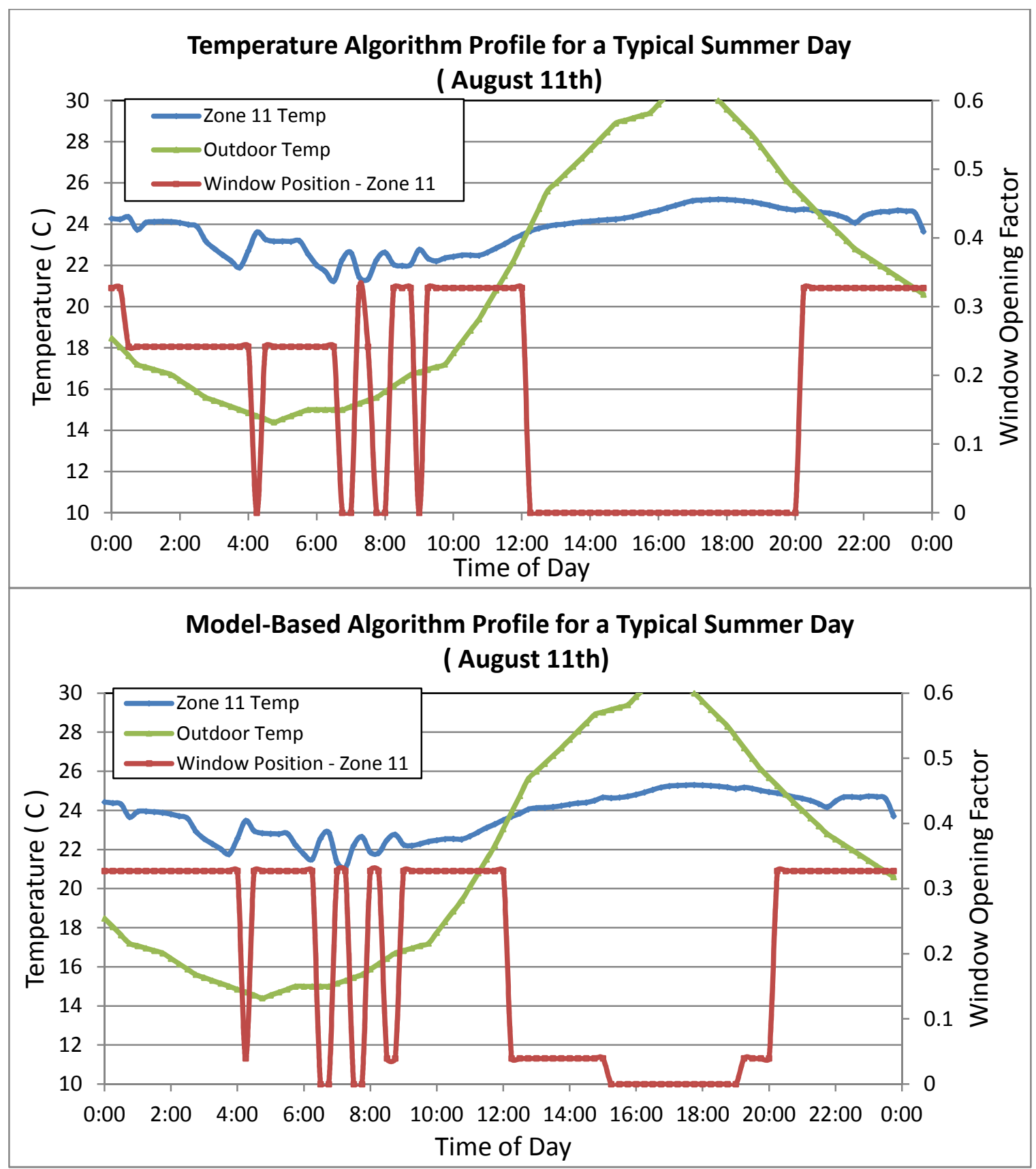

Figure 16 Typical Summertime Window Operation Line Graph-Zone 11

One basic measure of overall natural ventilation effectiveness is the average

ventilation rate. Figure 17 shows the BHB floor plan mapped with the average ventilation rate for each dormitory zone over extended summer season. The MB 
controller provides a higher ventilation rate on average for every zone compared to the TB controller. For the TB controller, the floor average is $0.0502 \mathrm{~m}^{3} / \mathrm{s}$, ranging from 0.0302 to $0.1365 \mathrm{~m}^{3} / \mathrm{s}$. The MB controller produces a floor average of $0.0535 \mathrm{~m}^{3} / \mathrm{s}$, ranging from 0.0338 to $0.1370 \mathrm{~m}^{3} / \mathrm{s}$. Figure 17 shows the consistent pattern of corner zones having significantly higher ventilation than a typical dormitory. This is the result of increased external wall area and operable window area.

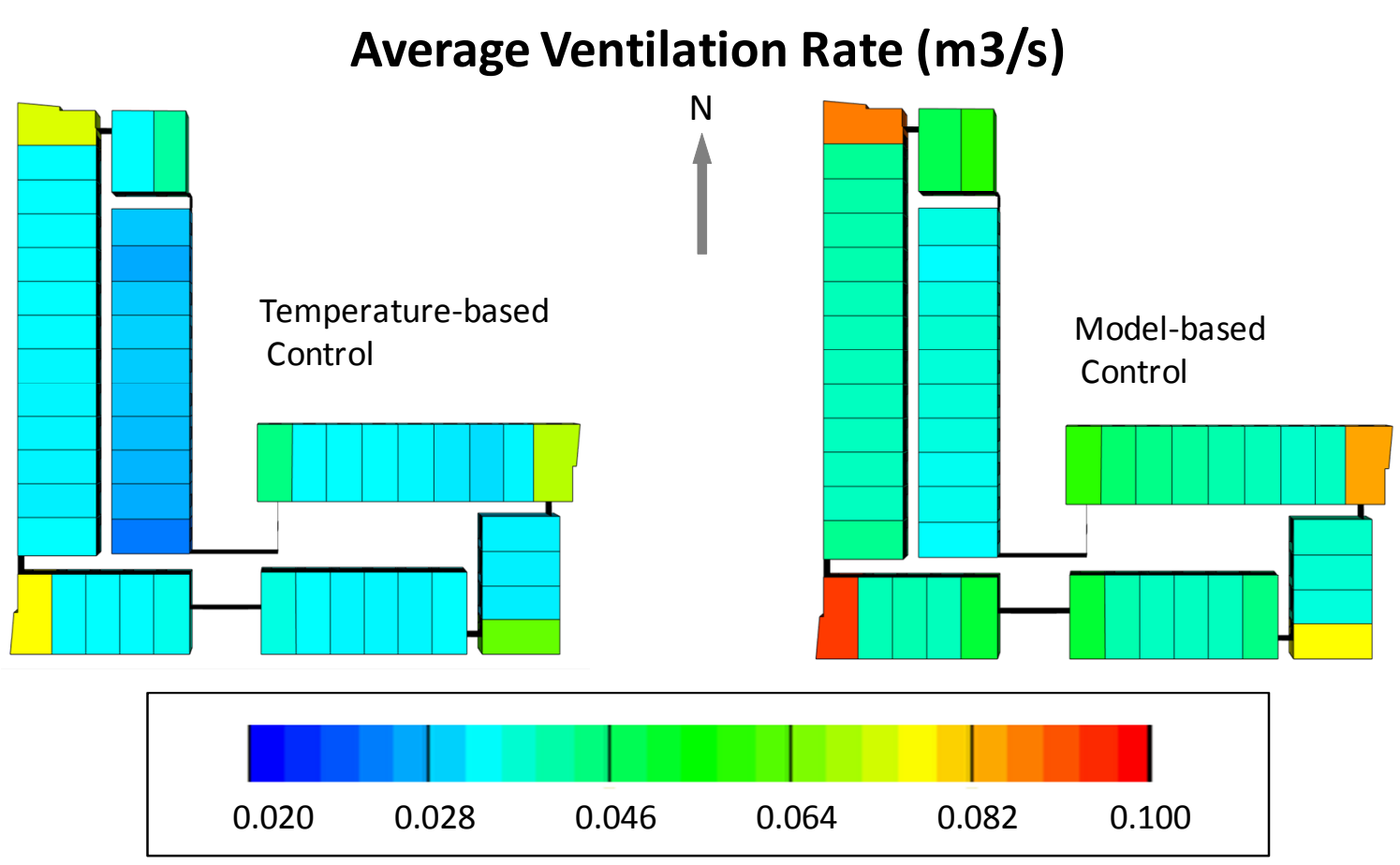

Figure 17 - Summer Average Ventilation Comparison 
Figure 18 shows the accumulated under-ventilated hours for each zone for both control strategies. The average under-ventilated hours for the entire floor is 741 for the TB controller, which represents $25 \%$ time of the summer. The MB controller is able to reduce this to only 197 hours. This is a 74\% reduction in under-ventilation.

\section{Hours Under-Ventilated}
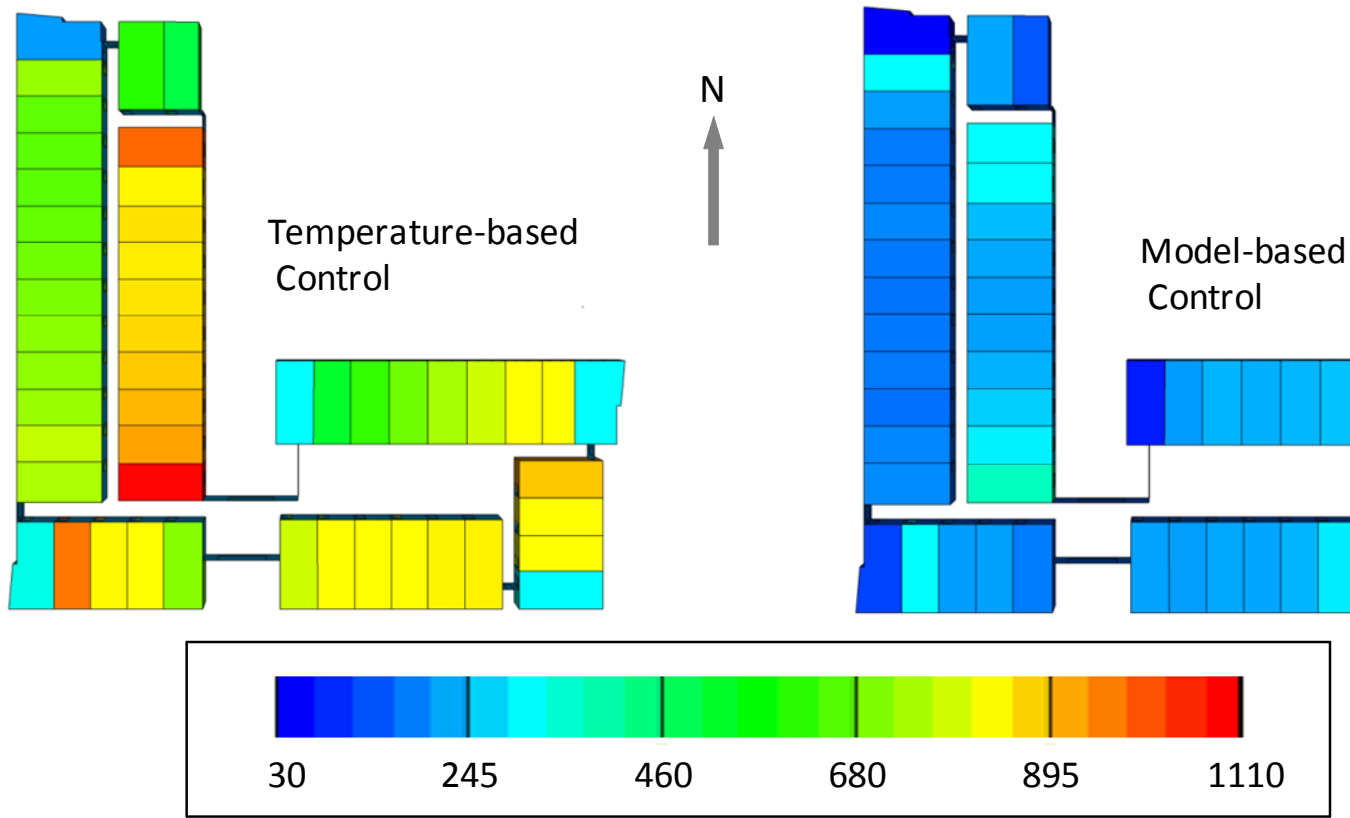

Figure 18 Summer Hours Under-Ventilated Comparison 
Figure 19 shows the histogram of ventilation rate when a zone is under-

ventilated for both controllers. This is a convenient way of gauging the magnitude of under-ventilation that is likely to occur. It is interesting to note that in the case of the MB controller, during $87 \%$ of the under-ventilated time the ventilation rate exceeds $0.0071 \mathrm{~m}^{3} / \mathrm{s}$, the minimum rate for one occupant. In the case of the TB controller, this figure drops to $80 \%$. The results suggest that although under-ventilation occurs, the living spaces are adequately ventilated for at least one person most of the time.

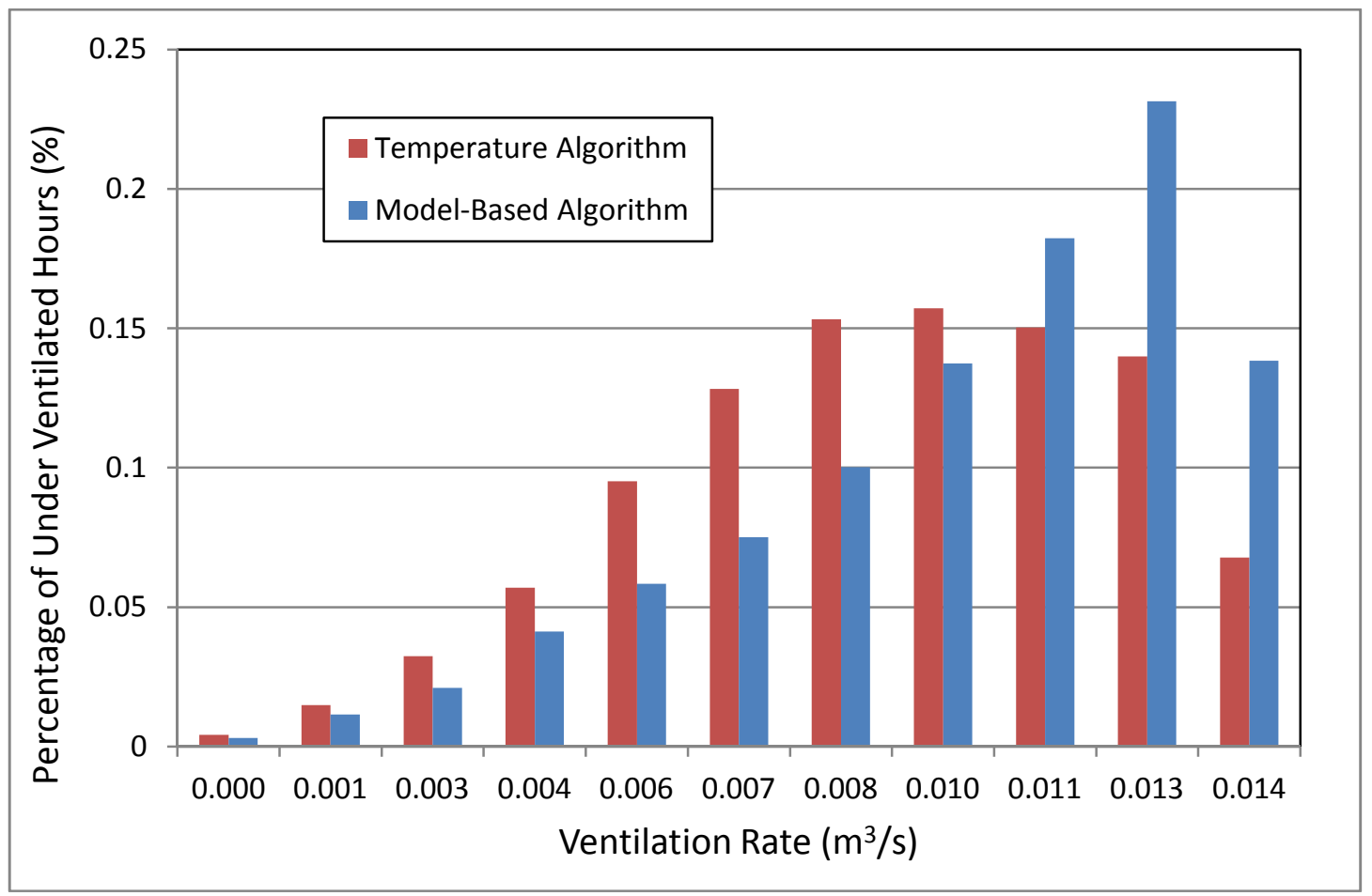

Figure 19 Distribution of Flowrate when Under-Ventilated for Summer 
Figure 20 shows under-ventilated hours for the MB strategy using a separate scale. It shows that while most zones have a low number of under-ventilated hours, there are several that consistently under-perform compared to the rest of the floor. Two zones, in particular, under-perform significantly, with more than twice the average number of under-ventilated hours (the two rooms in red in Figure 20). Further analysis shows that these zones are under-ventilated even when the window is open to the first position. This suggests that the window need to be opened beyond the first position in some cases. Future work could address this issue with a feedback loop or another optimization approach.

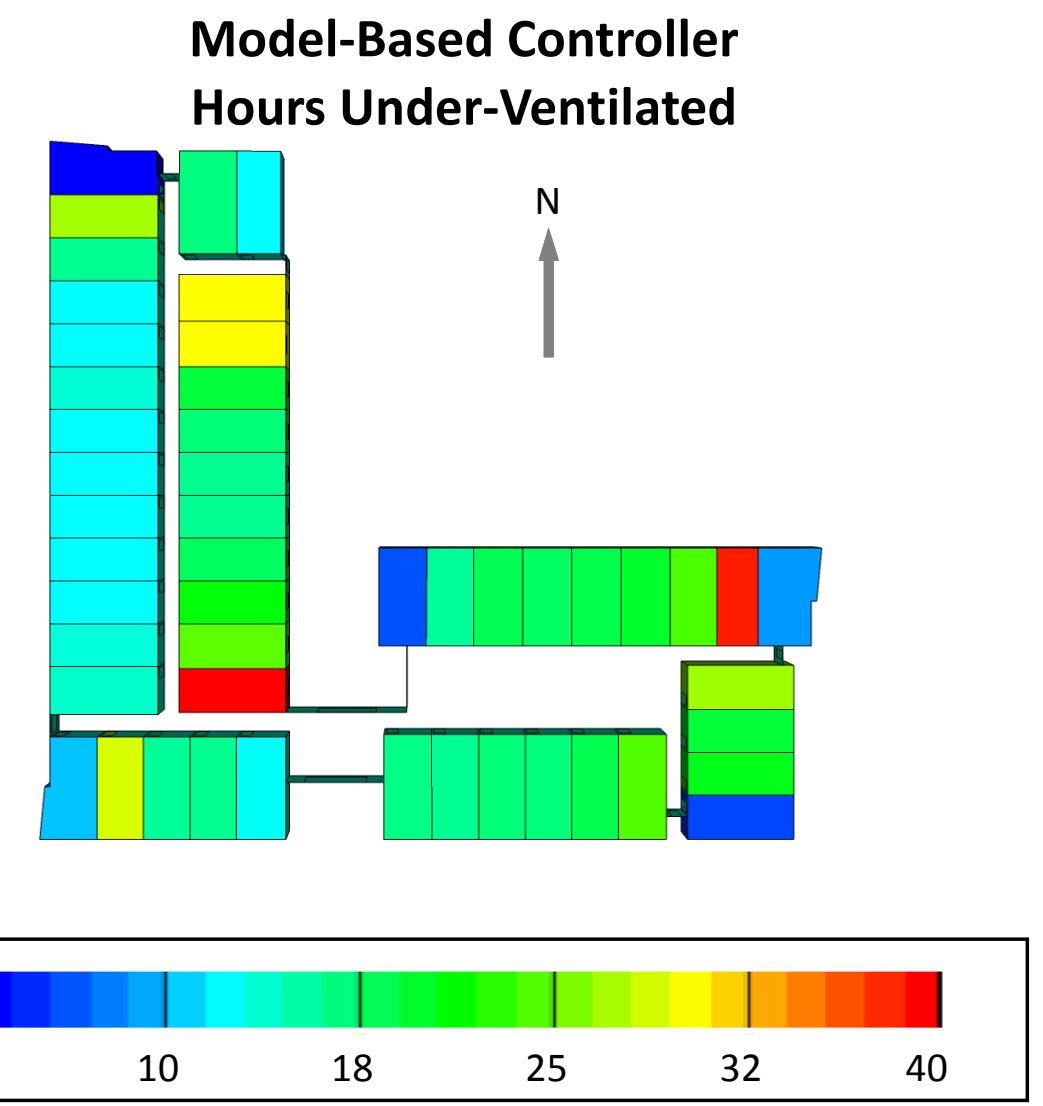

Figure 20 Summer Hours Under-Ventilated for the MB Controller 52 


\subsubsection{Thermal Comfort Performance}

This section presents a comparison of the resulting thermal comfort performance from the two controllers over the extended summer season. Figure 21 compares the number of over-heated hours, by zone, that each control strategy produces. It shows that while both control scenarios results in a relatively low number of over-heated hours, the TB controller results in a smaller number of over-heated hours in each zone compared to the MB controller. The average over-heated hours for the seventh floor is 27 (ranging from 0 to 103) and 35 (ranging from 0 to 106) for the TB and MB controllers, respectively. This represents $0.9 \%$ of the simulated hours for the TB controller and $1.1 \%$ for the MB controller.

\section{Hours Over-Heated}

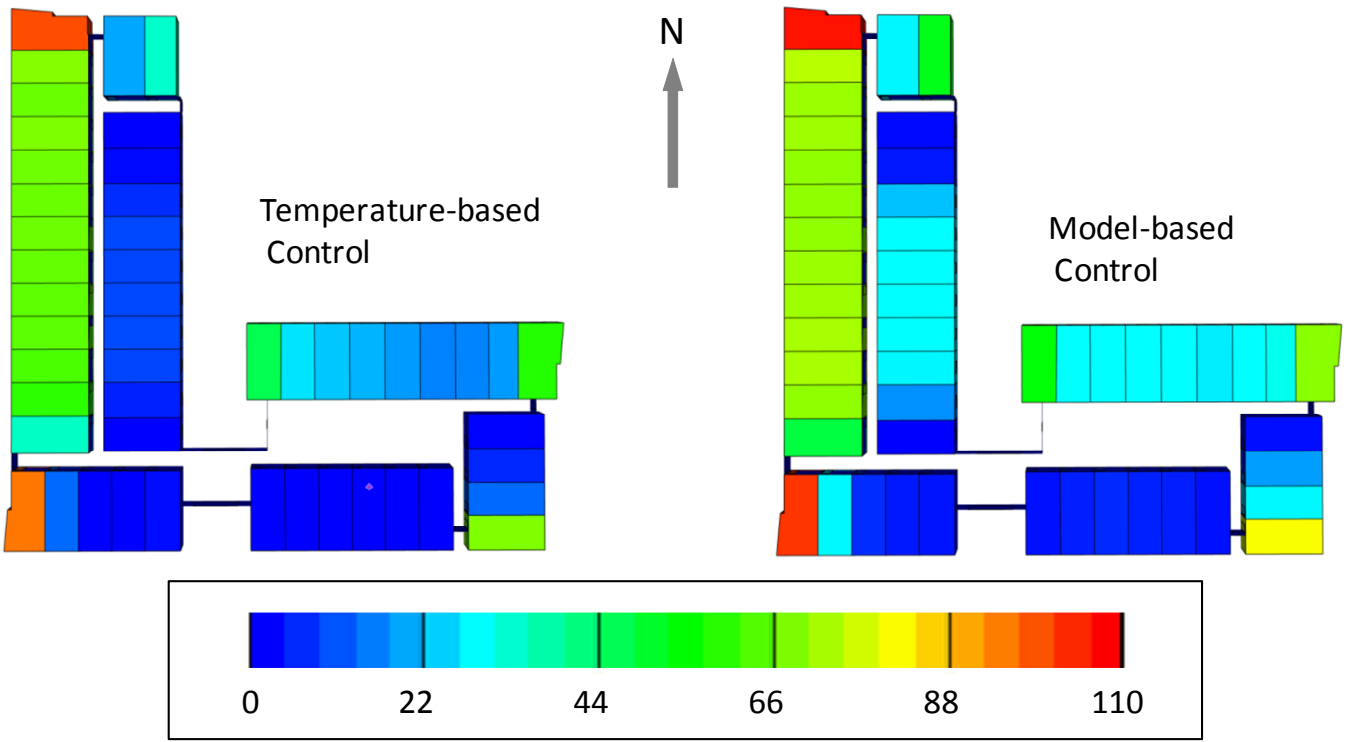

Figure 21 Summer Hours Over-Heated 
Figure 22 shows the number of over-heated degree-hours produced by the two control strategies. Again, the controllers have nearly identical performance, but the TB controller has slightly better performance in each zone. The average number of overheated degree-hours is 21 (ranging from 0 to 144) for the TB controller and 25 (ranging from 0 to 143) for the MB controller.

\section{Degree-Hours Over-Heated}

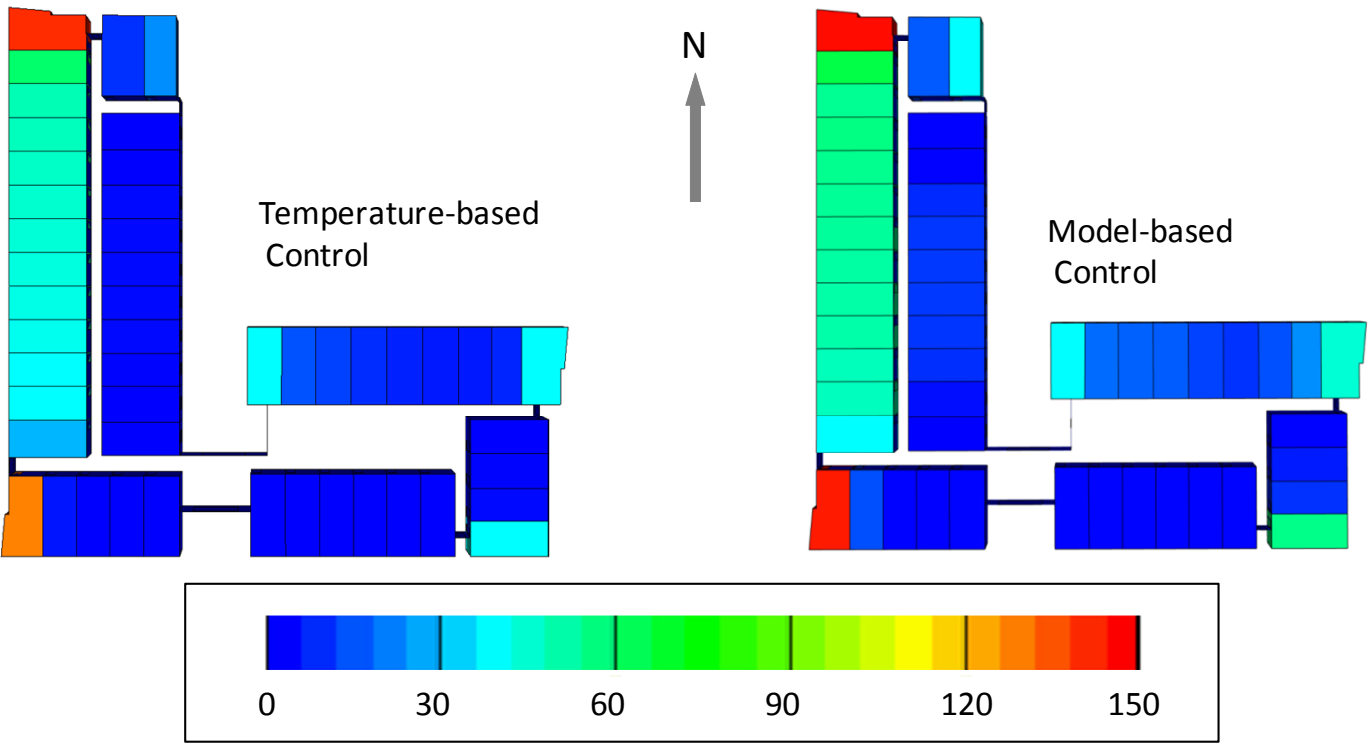

Figure 22 Summer Degree-Hours Over-Heated

As mentioned in the Ventilation Performance section, the less perfect thermal comfort performance is expected when using the MB controller. The MB controller prioritizes ventilation ahead of thermal comfort, which means that even when the outdoor temperature is higher than the zone temperature, the MB controller still allows windows to open in order to meet the ventilation requirement. During the summer season, there is no energy penalty for allowing this unfavorable air into the space 
because the BHB's systems provide no active cooling to dormitory zones. Instead, the penalty is paid in terms of thermal comfort, and the zone temperature rises.

\subsection{Winter Ventilation Performance Results}

In this section, the ventilation performance of the two controllers will be compared in terms of the average ventilation, under-ventilated hours, and the distribution of under-ventilated flow rates over the course of the winter months (October through May).

Figure 23 shows a snapshot of window opening factor, zone temperature, and ambient temperature for a typical winter day in BHB unit 11. It shows that while the TB controlled zone keeps the window closed throughout the day, the MB controller opens the window for several periods of time throughout the day. The MB controller opens the window when the algorithm predicts that under-ventilation will occur with the window closed. It should be noted the zone temperature does dip slightly when the window is open for minimum ventilation. This is because the heating load brought by the cold outside air entering zone is temporarily larger than the capacity of the baseboard heater. 


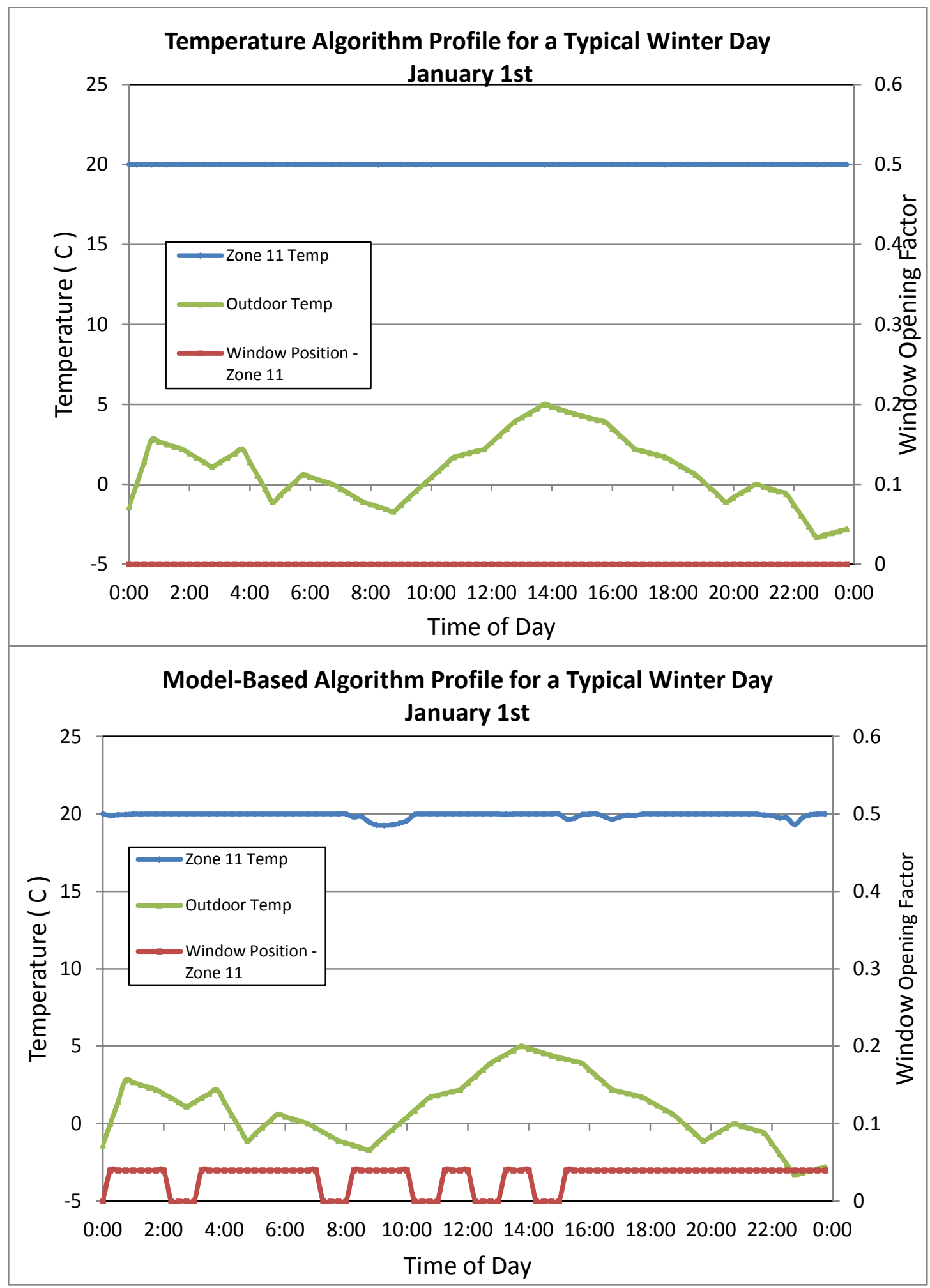

Figure 23 Typical Wintertime Window Operation Line Graph-Zone 11 
Figure 24 shows the average ventilation rate for each dormitory zone over the 8 month extended winter season. Similar to what happens during the summer season, MB controller provides a higher average rate for every zone. For the MB controller, the floor average flowrate is $0.0633 \mathrm{~m}^{3} / \mathrm{s}(134 \mathrm{CFM})$ with a maximum of $0.1159 \mathrm{~m}^{3} / \mathrm{s}(246 \mathrm{CFM})$ and a minimum of $0.0455 \mathrm{~m}^{3} / \mathrm{s}$ (96 CFM). The floor average flowrate for the TB controller is $0.0354 \mathrm{~m}^{3} / \mathrm{s}\left(75\right.$ CFM) with a maximum of $0.0852 \mathrm{~m}^{3} / \mathrm{s}(181 \mathrm{CFM})$ and a minimum of $0.0203 \mathrm{~m}^{3} / \mathrm{s}$ (42 CFM). For all zones in both cases, the average flowrate is well above the minimum requirement of $0.0142 \mathrm{~m}^{3} / \mathrm{s}$.

\section{Average Ventilation Rate (m3/s)}
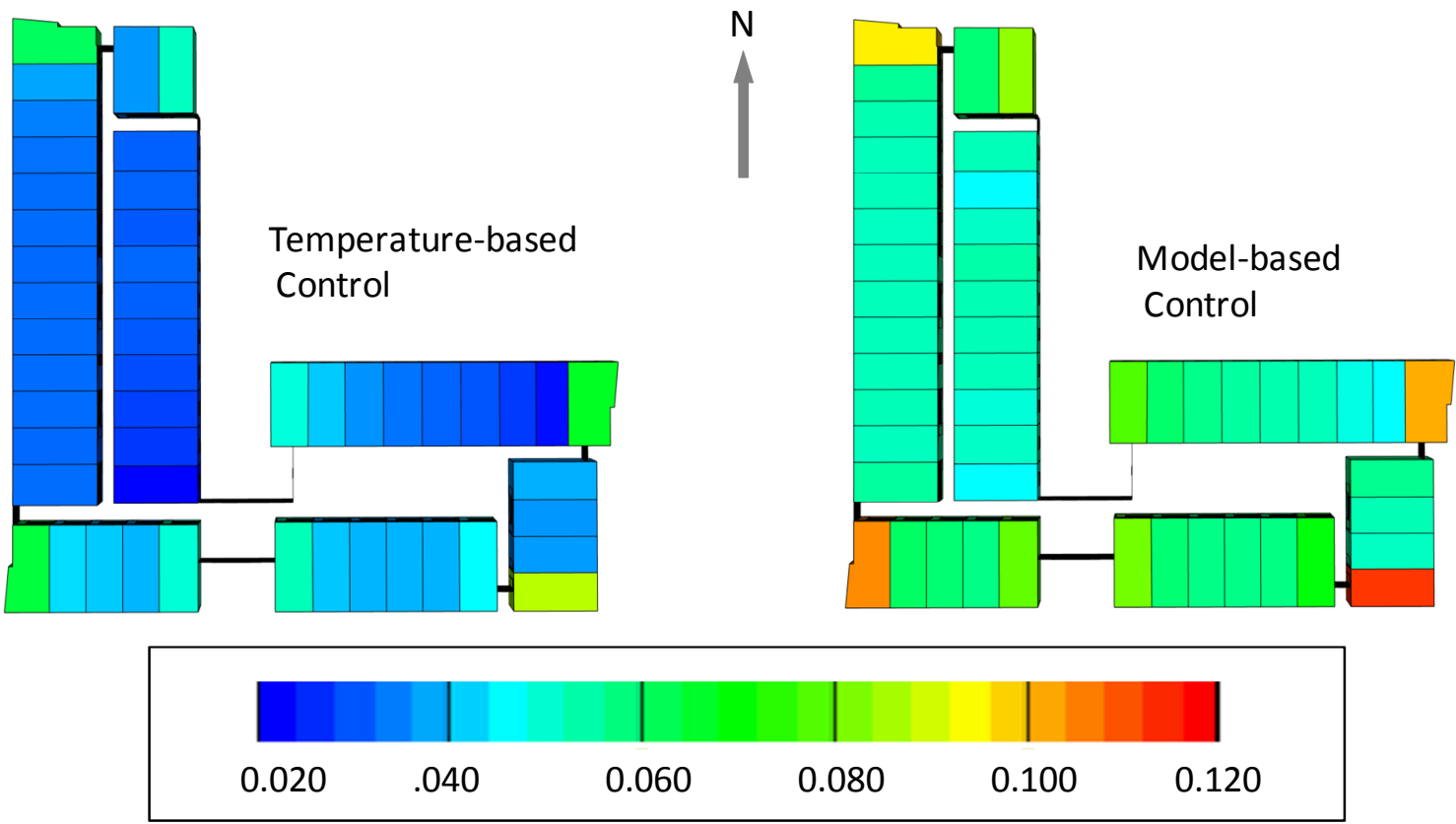

Figure 24 Winter Average Ventilation Rate 
Figure 25 compares the under-ventilated hours for both controllers during the winter months. Again, the MB controller performs significantly better, which results only 159 under-ventilated hours (ranging from 21 to 521 hours). Compared with the TB controller's average of 2745 hours (ranging from 700 to 4367), that is a reduction of 95\%. For the MB controller, under-ventilated hours represent less than $2.4 \%$ of the simulated hours, while the TB controller results in $47 \%$ of the winter hours being underventilated.

\section{Hours Under-Ventilated}

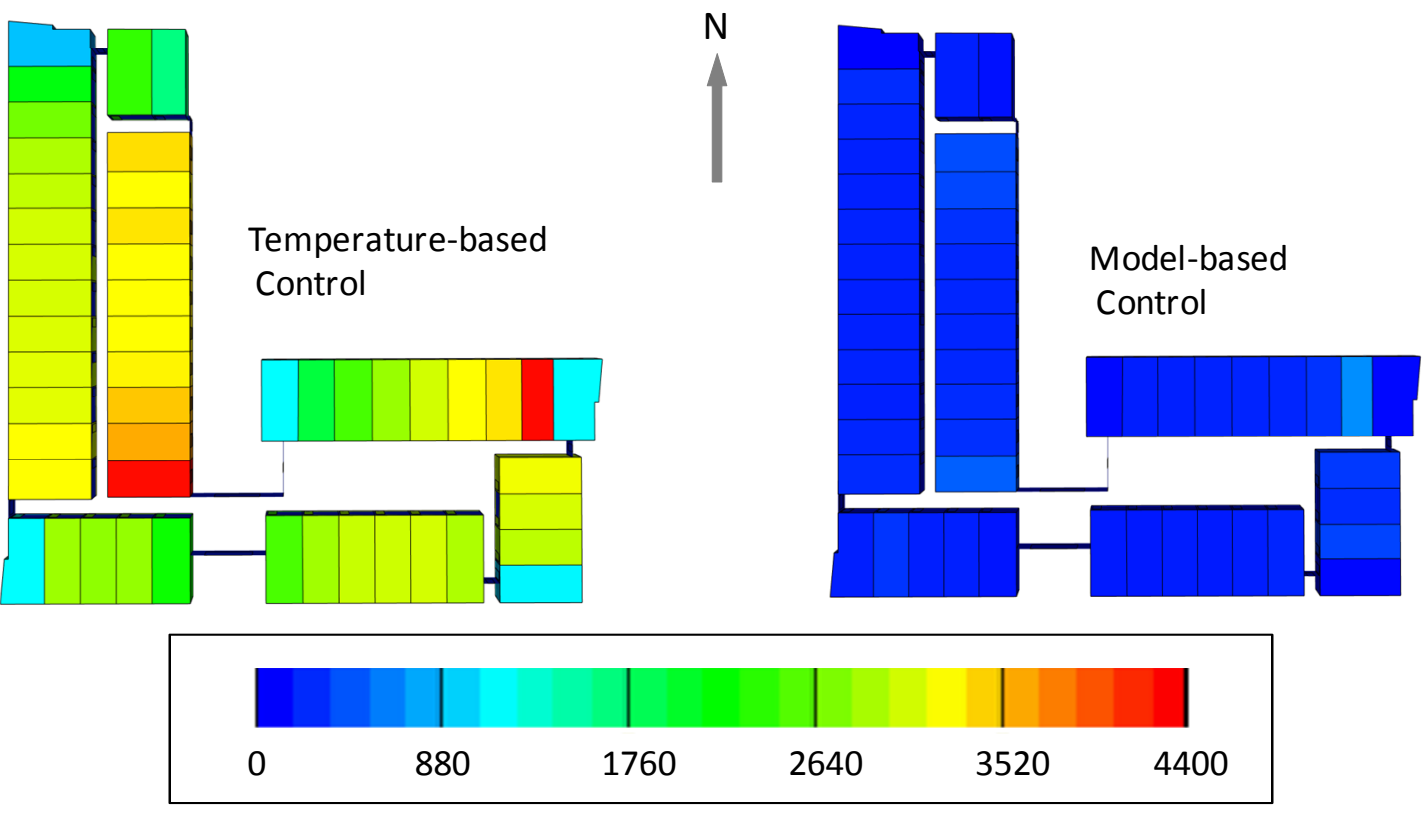

Figure 25 Winter Hours Under-Ventilated 
Figure 26 shows the under-ventilated hours for the MB controller on a separate color scale. It shows the same two zones that under-ventilate significantly during the summer have the same issue during the winter. These zones under-ventilate even when the window is open. Future work will attempt to solve these types of problem with a feedback loop.

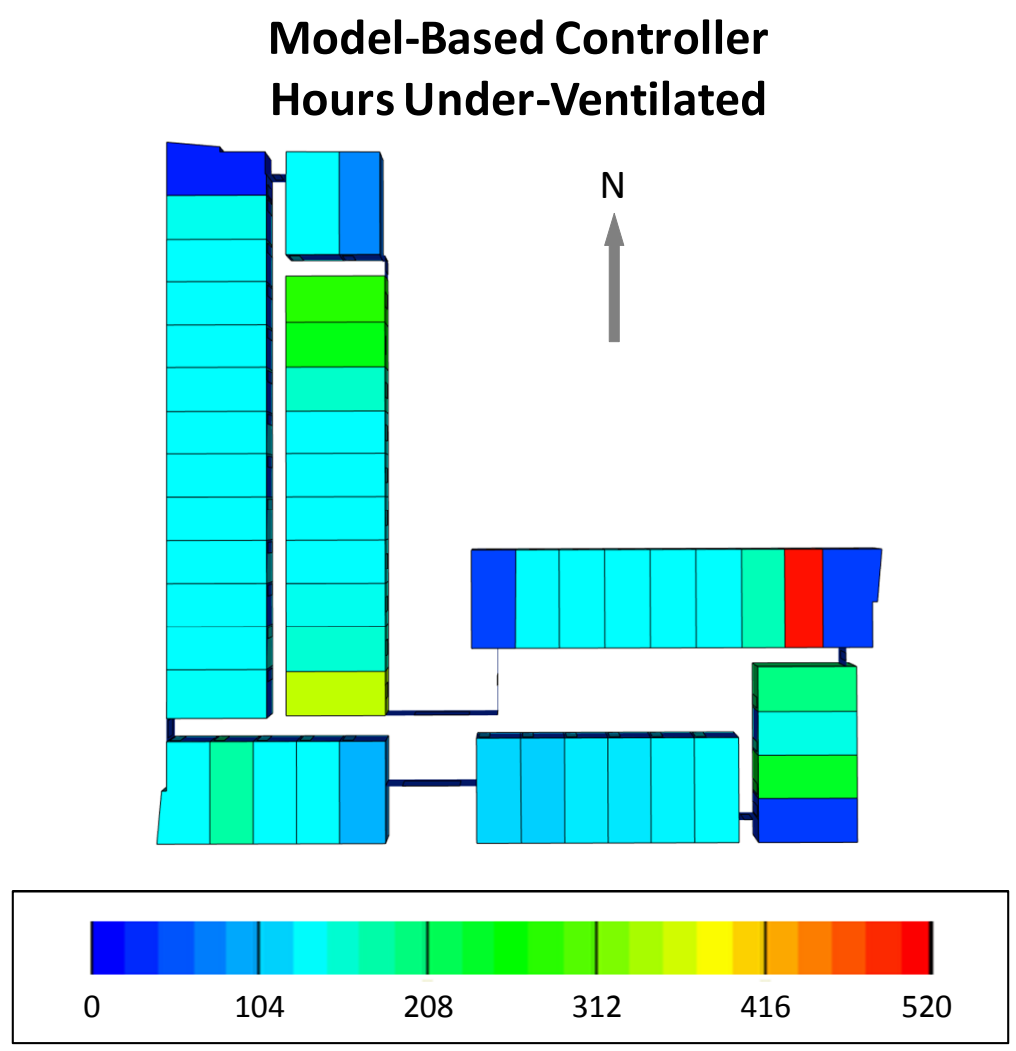

Figure 26 Winter Hours Under-Ventilated for the MB Controller

Figure 27 shows the histograms of flow rates when a zone is under-ventilated for both controllers. In the case of the MB controller, of $93.3 \%$ of the under-ventilated time, the ventilation rate exceeds $0.0071 \mathrm{~m}^{3} / \mathrm{s}$, the minimum rate for one occupant. For the 
TB controller, this figure drops to $89 \%$. Although under-ventilation occurs, the living spaces are usually adequately ventilated for at least one person.

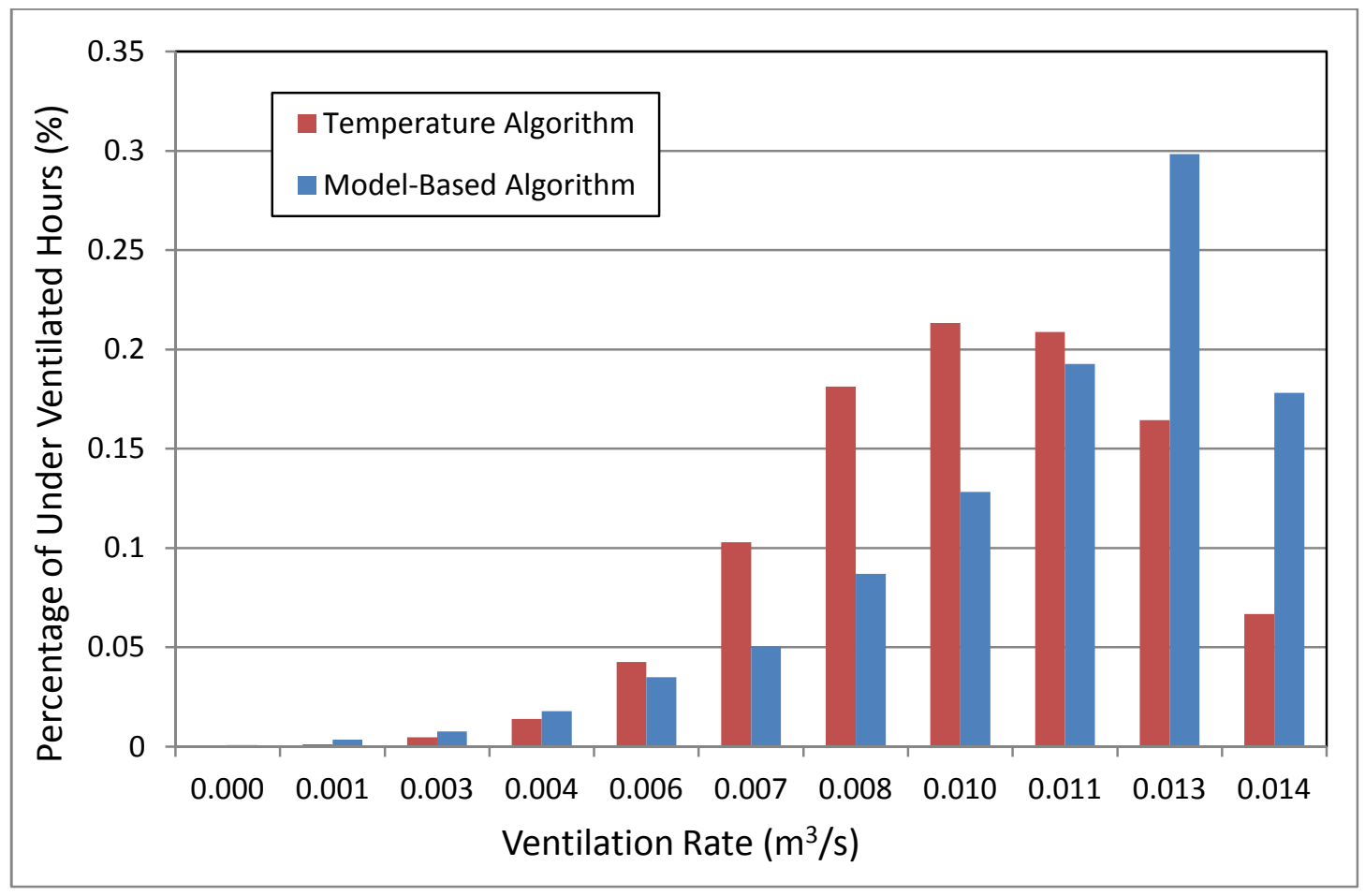

Figure 27 Distribution of Flowrate when Under-Ventilated for Winter

\subsection{Energy Performance Results}

This section presents an energy comparison between the two controllers

discussed thus far, as well as to a baseline conventional HVAC system. The results are presented as annual electricity cost at current market rate and are also broken down into Kilowatt-hours per zone per year. An EnergyPlus simulation was completed for each of the models using the 365-day TMY3 weather dataset for Portland, OR.

Table 4 compares the annual energy cost for the entire building amoung the three models. The cost of electricity is assumed to be $\$ 0.08 / \mathrm{kwh}$. The TB strategy 
consumes considerably less energy than the other two cases, since it does not ensure ventilation. The MB strategy results in an electricity bill of $\$ 84,670$, all of which is consumed during the winter months. The heat pump system costs $46 \%$ more than $\mathrm{MB}$ configuration, but ventilates and conditions the space 24-hours a day. The MB controller actually cost slightly more per month during the winter, but requires no energy during the summer months.

Table 4 Annual Energy Comparison

\begin{tabular}{|c|c|cr|}
\hline Model & Annual Power Consumption (Kwh) & \multicolumn{2}{|c|}{ Annual Power Cost } \\
\hline TB Controller & 479,363 & $\$$ & $38,349.00$ \\
\hline MB controller & $1,039,425$ & $\$$ & $84,670.00$ \\
\hline Heat Pump & $1,378,800$ & $\$$ & $123,304.00$ \\
\hline
\end{tabular}

Figure 28 compares the annual electricity consumption for each zone on the $7^{\text {th }}$ floor between the MB and TB controller. Since the ideal load system is centralized, it cannot be compared on a zone-by-zone basis. It can be seen that, in both cases, corner zones consume significantly more heating energy than the typical dormitory. This is due to the fact that corner zone have multiple external walls, which greatly increases uncontrolled infiltration. Also, these zones have multiple windows, and therefore crossflow ventilation occurs. As mentioned previously, neither the MB nor TB controller have been optimized for cross-flow. Tweaking the algorithms could help to reduce this extra cost, but these zones will fundamentally consume more energy based on their position on the building. 


\section{Yearly Power Consumption (kwh)}

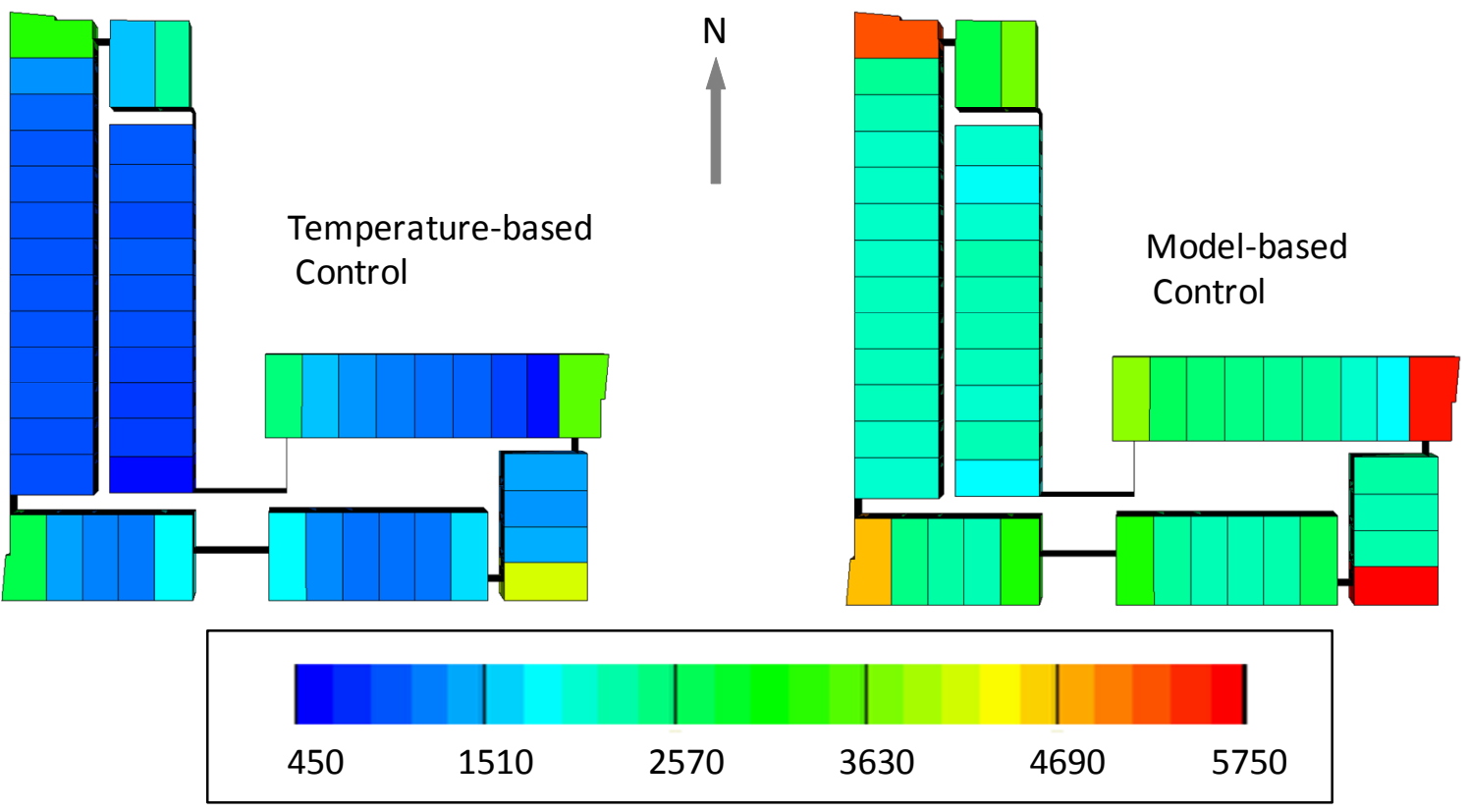

Figure 28 Energy Consumption Comparison

\subsection{Entire Building Statistics}

The ventilation and thermal comfort performance statistics for the 49 zones on each floor are averaged by floor in Table 5. The general trend is that floors at higher elevations experience higher ventilation rates. This is a result of the urban wind speed profile used in EnergyPlus, where wind velocity increases exponentially with height above the ground. The stronger wind is beneficial when conditions are appropriate for cooling, but ultimately results in greater uncontrolled infiltration. This causes more over-heating during the summer and greater power consumption during the winter for floors at higher elevations. This could be improved with future work to tune the predictor correction factor. 
Table 5 Entire Building Statistics

\begin{tabular}{|c|c|c|c|c|c|c|c|c|c|c|}
\hline \multicolumn{11}{|c|}{ Zone Average Statistics per Floor for Entire Year } \\
\hline \multirow[t]{2}{*}{ Floor } & \multicolumn{2}{|c|}{$\begin{array}{l}\text { Average } \\
\text { Ventilation } \\
\text { Rate }\end{array}$} & \multicolumn{2}{|c|}{$\begin{array}{c}\text { Under- } \\
\text { Ventilated } \\
\text { Hours }\end{array}$} & \multicolumn{2}{|c|}{$\begin{array}{c}\text { Over- } \\
\text { heated } \\
\text { Degree } \\
\text { Hours }\end{array}$} & \multicolumn{2}{|c|}{$\begin{array}{l}\text { Over- } \\
\text { Heated } \\
\text { Hours }\end{array}$} & \multicolumn{2}{|c|}{ KWh } \\
\hline & TB & MB & TB & MB & TB & MB & TB & MB & TB & MB \\
\hline 3 & 0.0273 & 0.0405 & 4324 & 504 & 16.9 & 21.9 & 24.8 & 31.9 & 933 & 2377 \\
\hline 4 & 0.0288 & 0.0421 & 4012 & 428 & 17.9 & 23.2 & 25.5 & 32.8 & 1022 & 2464 \\
\hline 5 & 0.0302 & 0.0436 & 3757 & 363 & 19.0 & 24.4 & 26.2 & 33.9 & 1106 & 2546 \\
\hline 6 & 0.0317 & 0.0454 & 3532 & 322 & 20.0 & 25.7 & 26.8 & 34.7 & 1192 & 2643 \\
\hline 7 & 0.0324 & 0.0461 & 3540 & 355 & 20.8 & 25.4 & 27.4 & 35.2 & 1222 & 2652 \\
\hline 8 & 0.033 & 0.0464 & 3410 & 315 & 21.7 & 27.1 & 27.6 & 35.3 & 1256 & 2673 \\
\hline 9 & 0.0336 & 0.0470 & 3338 & 303 & 22.2 & 27.5 & 27.9 & 35.8 & 1288 & 2693 \\
\hline 10 & 0.0342 & 0.0477 & 3265 & 289 & 22.6 & 28.3 & 28.4 & 36.4 & 1314 & 2731 \\
\hline $\begin{array}{l}\text { Building } \\
\text { Average }\end{array}$ & 0.0314 & 0.0448 & 3647 & 355 & 20.1 & 25.6 & 26.8 & 34.5 & 1167 & 2597 \\
\hline
\end{tabular}




\section{Conclusions}

Natural ventilation is an effective passive cooling strategy and has been shown to be able to significantly reduce both the operating energy and the capital cost. The challenge is to actively control natural ventilation to provide ventilation and passive cooling throughout the year without introducing unnecessary heating and cooling loads due to over-ventilation. This research has developed a fully automated model-based controller for natural ventilation through operable windows that ensures both ventilation and thermal comfort needs to be met in built environment. A student dormitory building, located in Portland, Oregon, has been used as a case study to demonstrate the performance of the proposed controller.

The basic function of this model-based controller is to predict the air volume entering each zone through the operable windows based on readily measureable zone and outdoor conditions. Window control decisions are then determined based on the predicted flowrate and desired zone conditions. This type of proactive control helps significantly increase the ventilation performance, compared to other natural ventilation controllers, while maintaining very good thermal comfort performance. In addition, the yearly energy cost is reduced by $33 \%$ for zones under model-based control, compared to a conventional heat pump system.

The model-based flowrate predictor has been enhanced by introducing a linear correction factor and a $\left(\mathrm{C}_{\mathrm{p}}{ }^{*} \mathrm{~V}^{2}\right)$ parameter through further statistical analysis of simulation results. The linear relationship, discovered between predicted airflow 
through the adopted airflow calculation method and the "actual" airflow estimated through a more sophisticated building energy model with fully integrated airflow network, indicates practical applicability of the proposed controller.

The simulation results show that there is good potential to integrate the developed model-based controller in densely zoned buildings, such as dormitories and hotels, which utilize single-sided ventilation. When deployed in an appropriate climate zone, this control strategy is able to effectively cool the living spaces during the summer without the use of mechanical assistance. During the winter, the MB controller is able to maintain ventilation requirements without significant over-cooling. The resulting reduction in yearly energy consumption could be further improved by replacing the electric baseboard heaters in the case study building with a more efficient water-based system.

A feedback loop that could be easily implemented in a real-world application of this proposed controller, which would eventually improve the flowrate predictor to provide a more reasonable estimate of the actual airflow rate through the operable windows. This optimization could be performed for each independent zone, which would help to reduce the performance variability among zones at different locations.

The overarching contributions of this research are summarized in the bulleted list below: 
- Development a flowrate predictor correction factor using linear regression

- Development of a natural ventilation control parameter combining the wind pressure coefficient $\left(C_{p}\right)$ and wind speed (that determines if ventilation requirements will be met with infiltration alone)

- Development of a model-based natural ventilation controller that effectively balances ventilation requirements, thermal comfort, and energy consumption throughout the year 


\section{References}

Allard, F. \& Santamouris, M., 1998. Natural ventilation in buildings: a design handbook, Earthscan/James \& James.

Allocca, C., Chen, Q. \& Glicksman, L.R., 2003. Design analysis of single-sided natural ventilation. Energy and Buildings, 35(8), pp.785-795.

ASHRAE, 1997. 1997 ASHRAE Handbook - Fundamentals, Atlanta, GA: American Society of Heating, Refrigerating and Air-Conditioning Engineers Inc.

ASHRAE, 2004a. ANSI/ASHRAE Standard 62.1-2004 - Ventilation for Acceptable Indoor Air Quality., Atlanta, GA: ASHRAE, Inc.

ASHRAE, 2004b. ASHRAE Standard 55-2004. Thermal environmental conditions for human occupancy. American Society of Heating, Refrigerating and AirConditioning Engineers, Inc. Atlanta, GA.

Axley, J.W., 2001. Application of Natural Ventilation for US Commercail Buildings, U.S. Department of Energy Office of Building Systems.

Brager, G. \& Baker, L., 2009. Occupant satisfaction in mixed-mode buildings. Building Research \& Information, 37(4), pp.369-380.

Costola, D., Blocken, B. \& Hensen, J.L.M., 2009. Overview of pressure coefficient data in building energy simulation and airflow network programs. Building and Environment, 44(10), pp.2027-2036.

Crawley, 2000. EnergyPlus: energy simulation program. ASHRAE journal, 42(4), pp.49-56.

Daly, A., 2002. Operable windows and HVAC system. Heating/Piping/Air Conditioning Engineering, 74(12), p.22(8).

DOE, 2009. Buildings Energy Data Book. Available at: http://buildingsdatabook.eren.doe.gov/TableView.aspx?table=1.2.4 [Accessed May 29, 2011].

Eftekhari, M.M. \& Marjanovic, L.D., 2003. Application of fuzzy control in naturally ventilated buildings for summer conditions. Energy and buildings, 35(7), pp.645655.

Evola, G. \& Popov, V., 2006. Computational analysis of wind driven natural ventilation in buildings. Energy and buildings, 38(5), pp.491-501. 
De Gids, W. \& Phaff, H., 1982. Ventilation rates and energy consumption due to open windows: A brief overview of research in the Netherlands. Air infiltration review, 4(1), pp.4-5.

Google Inc, 2011. Google Earth, Available at: www.google.com/earth/index.html.

Gross, S. \& Hu, H., 2011. A Feasibility Study of Natural Ventilation in a Midrise Student Dormitroy Buidling. In Building Simulation Conference 2011.

Gu, L., 2007. Airflow network modeling in EnergyPlus. In Proceedings: Building Simulation Conference 2007.

Knoll, B., Phaff, J. \& de Gids, WF, 1995. Pressure Simulation Program. In Preccedings of the conference on implementing the results of ventilation research. AIVC.

Larsen, T.S. \& Heiselberg, P., 2008. Single-sided natural ventilation driven by wind pressure and temperature difference. Energy and Buildings, 40(6), pp.10311040.

MathWorks Inc, 1992. MATLAB,

May-Ostendorp, P. et al., 2010. Model-predictive control of mixed-mode buildings with rule extraction. Building and Environment.

McDowell, T.P. et al., 2003. Integration of airflow and energy simulation using CONTAM and TRNSYS. TRANSACTIONS-AMERICAN SOCIETY OF HEATING REFRIGERATING AND AIR CONDITIONING ENGINEERS, 109(2), pp.757-770.

Mehta, M., 2005. Natural ventilation analyses of an office building with open atrium. In 9 th IBPSA Conference, Montreal. pp. 741-746.

Moody, S., 2009. Non-Integrated Operable Windows: Occupant Interaction \& Energy Impact, Portland, OR: Portland State University - Green Building Research Lab.

NCM, 2009. NCM: National Calculation Method. Available at: http://www.ncm.bre.co.uk/page.jsp?id=1 [Accessed May 27, 2011].

Redlich, C.A., Sparer, J. \& Cullen, M.R., 1997. Sick-building syndrome. The Lancet, 349(9057), pp.1013-1016.

RETScreen, 2005. RETScreen Software Online User Manual.

Spindler, H.C. \& Norford, L.K., 2007. Naturally ventilated and mixed-mode buildings-Part II: Optimal control. Building and Environment, 44(4), pp.750-761. 
Tindale, A., 2005. DesignBuilder Software. Stroud, Gloucestershire, DesignBuilder Software Ltd.

Torcellini, P.A. et al., 2006. Lessons learned from field evaluation of six high-performance buildings, National Renewable Energy Laboratory.

Walton, GN \& Dols, W., 2006. CONTAM 2.4b user guide and program documentation.

Wetter, M. \& Haves, P., 2008. A Modular Building Controls Virtual Test Bed for the Integrations of Heterogeneous Systems.

Wilcox, S. \& Marion, W., 2008. Users manual for TMY3 Data Sets, National Renewable Energy Laboratory. 